\section{Cuadernos de} Investigación Histórica

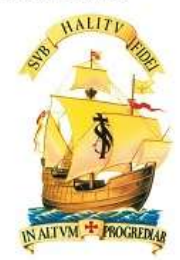

Cuadernos de Investigación Histórica $\mathrm{N}^{\mathrm{o}} 36$

La emperatriz Eugenia de Montijo: 100 años de la muerte de una española universal Año: 2020

DOI: https://doi.org/10.51743/cih.88

(c) (i) (8)

\title{
EUGENIA DE MONTIJO: APROXIMACIÓN HERMENÉUTICA A LA EMPERATRIZ EN LOS DISCURSOS DEL DUQUE DE ALBA EN OXFORD Y BARCELONA (1940-1947) EUGENIA DE MONTIJO: HERMENEUTIC APPROACH TO THE EMPERATRESS IN THE SPEECHES OF THE DUKE OF ALBA IN OXFORD AND BARCELONA (1940-1947)

\author{
José Luis Sánchez García \\ Director del Seminario de Historia Cisneros. \\ Fundación Universitaria Española \\ Juan María Díez Sanz \\ Profesor de Filosofía. \\ Universidad Católica de Valencia
}

\begin{abstract}
Agradecimientos:
Queremos agradecer a D. Enrique Kirkpatrick Mendaro y a su familia la deferencia de brindarnos acceso directo a su archivo familiar donde hemos podido consultar numerosa documentación para esta investigación.
\end{abstract}




\title{
Resumen
}

Tratamos de trazar los perfiles de una semblanza de Doña Eugenia, a partir de lo que hemos titulado "Una aproximación hermenéutica a los discursos de Oxford y Barcelona de 1940-47", del que fuera Duque de Alba y Director de la Real Academia de la Historia, su sobrino-nieto D. Jacobo Fitz-James Stuart y Falcó, sobre la que consideraba su abuela, la Emperatriz Eugenia de Montijo, a la que trató desde su infancia, en las diversas etapas y momentos de su vida, en una relación entrañable que culminó cuando la acogió en su propia casa, ya en España, al final de sus días.

Palabras clave: Duque de Alba, Jacobo Fitz-James Stuart y Falcó, Emperatriz Eugenia, Eugenia de Montijo

\begin{abstract}
We try to trace the profiles of a profile of Doña Eugenia, based on what we have entitled "A hermeneutical approach to the Oxford and Barcelona speeches of 1940-47", of the former Duke of Alba and Director of the Royal Academy of the History, his great-nephew D. Jacobo Fitz-James Stuart y Falcó, about whom he considered his grandmother, Empress Eugenia de Montijo, whom he treated from childhood, in the various stages and moments of his life, in a relationship endearing that culminated when he welcomed her into his own home, already in Spain, at the end of his days.
\end{abstract}

Keywords: Duque de Alba, Jacobo Fitz-James Stuart y Falcó, Eugenia de Montijo, Empress Eugenie 


\section{Contenido}

1. APROXIMACIÓN A LA FIGURA DE EUGENIA DE MONTIJO (1826- 1920) EN LOS DISCURSOS DEL DUQUE DE ALBA DE LOS AÑOS 40 -47. - 1.1. Los discursos de Oxford y Barcelona. - 1.2. Etapas de la vida de Eugenia. - 2. VIDA DE DOÑA EUGENIA ANTES DE CONOCER AL EMPERADOR. - 2.1. De su carácter a su linaje - 2.2. De su posición internacional -2.3 . De la circunstancia española a su marcha a Francia. - 3. VIDA DE DOÑA EUGENIA DE MONTIJO COMO EMPERATRIZ. - 3.1. Del encuentro al matrimonio imperial. - 3.2. Del nacimiento de su hijo a las dificultades matrimoniales. - 3.3. De las regencias de Francia al apoyo a Austria. - 3.4. Del declive personal a su presencia en grandes eventos históricos. - 4. TRAS LA MUERTE DEL EMPERADOR. - 4.1. De la muerte del Emperador a la del Príncipe. - 4.2. Del Exilio en Inglaterra a la I Guerra Mundial. - 4.3. Del sentido de su vida, desde la fe católica, al código de honor de la Emperatriz. - 5. CONCLUSIONES. - 6 . BIBLIOGRAFÍA CONSULTADA Y CITADA.

\section{Aproximación a la figura de Eugenia de Montijo (1826-1920) en los discursos del Duque de Alba de los año s 40 -47.}

Recordaba la prensa en fechas recientes que se cumplen 100 años del fallecimiento de una de las mujeres españolas más universales de la historia contemporánea con una relevante proyección en distintos planos (histórico, político, cultural, diplomático, social, etc.), que implica a diversas naciones europeas a las que queda ligada su figura, y que, paradójicamente, no han favorecido un conocimiento equilibrado y ponderado sobre su persona. Para tratar de ampliar el conocimiento de la vida de esta ilustre mujer y hacer justicia a su figura, nos hemos propuesto profundizar en su vida. ${ }^{1}$

Su nombre competo fue María Eugenia Ignacia Agustina de Palafox Portocarrero y Kirkpatrick, y su título originario, Condesa de Teba ${ }^{2}$, aunque fue conocida

${ }^{1}$ AMIGUET, T., "Eugenia de Montijo, La granadina que enamoró a un emperador", La Vanguardia, Barcelona, 10/07/2020. Disponible en

https:/www.lavanguardia.com/hemeroteca/20200710/482208290991/eugenia-de-montijo-emperatriz-francia-barraquer.html

2 Título nobiliario español creado y otorgado por Carlos I en favor de D. Diego Ramírez de Guzmán II, el 22 de octubre de 1522, hijo de D. Juan Ramírez de Guzmán, conquistador de la Villa de Teba en Málaga. Eugenia de Montijo fue la XX Condesa de Teba y su sobrina, María Eugenia Sol María Fitz-James Stuart y Falcó, fue la XXI con Grandeza de España, por cesión de su hermano Jacobo Fitz-James Stuart y Falcó, XVII Duque de Alba de Tormes y Director de la Real Academia de la Historia al que vamos a seguir en la semblanza trazada sobre su tía-abuela la Emperatriz Eugenia en el presente trabajo. 
popularmente en España como Eugenia de Montijo y en la historiografía europea como la Emperatriz Eugenia, por su preeminente posición como Emperatriz consorte de Francia tras su matrimonio con Napoleón III (1808 - 1873) que incluye tres periodos de regencia directa de los destinos de Francia y todas sus posesiones, asumidos por Eugenia de Montijo en distintos momentos críticos para la nación gala durante la época del II Imperio Francés (1852 - 1870).

\subsection{Los discursos de Oxford y Barcelona.}

Como es bien sabido, se ha escrito mucho sobre Doña Eugenia. La mayor parte, literatura sobre su persona o anécdotas en las que se recrea su vida, que se rememora incluso en coplas y canciones populares que muchos se saben y todavía cantan. Algunos de sus ecos e influjos estéticos todavía perduran, renovados, en las revistas de moda más actuales, que no dudan en califi arla como «la influencer española más internacional del siglo XIX». ${ }^{3}$

Con la presente investigación, nosotros queremos contribuir al conocimiento del personaje histórico que está detrás de esa figura icónica en la estética y en la moda, del personaje refinado que es objeto de la recreación literaria y de la figura entrañable que pervive en el imaginario popular. Por ello, nos hemos centrado en una de las aproximaciones más fidedignas y cercanas a su figura que existen en castellano, como son los discursos del Duque de Alba y Director de la Academia de Historia, D. Jacobo Fitz-James Stuart y Falcó, y hemos buscado en la extensa bibliografía extranjera el complemento más selecto y riguroso para la constatación de los hechos y circunstancias que el académico español refiere en sus discursos sobre Doña Eugenia realizados en los años 40.

En el presente trabajo vamos a seguir y analizar el discurso de D. Jacobo Fitz-James Stuart y Falcó, Duque de Alba, quien, siendo Director de la Real Academia de la Historia, miembro de la Real Academia Española y de la de Bellas Artes de San Fernando, pronunció sobre la figura de su familiar -la Emperatriz Eugenia de Montijo- ante la Academia de Doctores del Distrito Universitario de Barcelona en el curso 1946 - 47 en un documento de valor histórico que figura en el catálogo de la Biblioteca Nacional de España. ${ }^{4}$

${ }^{3}$ LUIS, N., "Eugenia de Montijo, cien años de la influencer española más internacional del s. XIX", Revista VOGUE, 11 de julio de 2020. Disponible en

https:/www.vogue.es/moda/articulos/eugenia-montijo-emperatriz-francia-legado-moda-worth-alta-costura-louis-vuitton

${ }^{4}$ ALBA, JACOBO FITZ-JAMES STUART Y FALCÓ, DUQUE DE, Discurso sobre la Emperatriz Eugenia en la Academia de Doctores del Distrito Universitario de Barcelona. Curso 1946-47, Diana Artes Gráficas, Madrid, 1947. Disponible en Biblioteca Nacional de España (BNE)

http://catalogo.bne.es/uhtbin/cgisirsi/0/x/0/05?searchdata1=bimo0000873997\{001\}\#ejemplares 
El discurso pronunciado en la Universidad de Barcelona en el curso 1946-7 por el Duque de Alba es una actualización de uno anterior, pronunciado en The Arc, en Oxford, en Inglaterra, en $1941^{5}$. Sobre su relación con Inglaterra cabe destacar que el Duque se había educado allí y que había recibido un doctorado honoris causa por la Universidad de Oxford, tal como refiere en el propio discurso $^{6}$. También alude a la circunstancia de que, al inicio de Guerra Civil Española, se encontraba precisamente en Inglaterra, visitando Campion Hall ${ }^{7}$, lo cual le evito algún importante contratiempo personal.

Son pocas las diferencias entre ambos discursos, recogidos en sendos documentos, si bien en el de Oxford de 1941 abundan las alusiones al contexto de la Guerra Civil Española (1936-39) que acababa de finalizar y cuyas heridas permanecían abiertas porque las secuelas del conflicto eran aún muy recientes.

La conferencia original en Oxford quedó recogida en el Boletín de la Real Academia de la Historia y está disponible en abierto en la Biblioteca Virtual Miguel de Cervantes ${ }^{8}$. Una vez más, queremos agradecer a estas instituciones la valiosa labor que realizan para conservar y dar a conocer documentación relevante sobre la historia de España, prestando un servicio a la sociedad que consideramos de primer orden cultural, tal como hemos expuesto y argumentado en otros documentos e intervenciones públicas. ${ }^{9}$

Nos hemos centrado más en el discurso de Barcelona por ser posterior y estar depurado de tantas alusiones a la circunstancia española de posguerra y al enfrentamiento fratricida de la Guerra Civil, que poco o nada aportan a la finalidad de nuestra aproximación hermenéutica a los mismos, que es profundizar en el conocimiento de Doña Eugenia.

La figura de la Emperatriz Eugenia tiene entidad por sí misma para ser ob-

\footnotetext{
${ }^{5}$ Idem, La Emperatriz Eugenia / el Duque de Alba: Conferencia pronunciada en «The Ark», Oxford, 15 de julio de 1941, Biblioteca Virtual Miguel de Cervantes, Alicante, 2012. Disponible en http://www.cervantesvirtual.com/obra/la-emperatriz-eugenia/

${ }^{6}$ Ibidem, p. 197.

${ }^{7}$ Ibidem.

${ }^{8}$ Ibidem.

${ }^{9}$ Agradecimiento que hemos realizado públicamente y en persona a la Directora de la Real Academia de la Historia, Dña. Carmen Iglesias Cano, en sus intervenciones en la sede de la Fundación Universitaria Española en Madrid, como pudo constatarse en el Congreso de la Conmemoración del 500 aniversario de la Primera Circunnavegación de la Tierra, celebrado los días 23 y 24 de octubre de 2019, tal como realizó el director del Seminario de Historia Cisneros de la FUE, D. José Luis Sánchez en la presentación de su conferencia, disponible en https://www.youtube.com/watch?v=tNRr-UC2nLU\&t=3304sy y el filósofo D. Juan Díez Sanz, por su parte, en su intervención sobre los presupuestos gnoseológicos y los referentes éticos y morales que hicieron posible la circunnavegación de la Tierra, disponible en https:/www.youtube.com/watch?v=bV35cQoSldM\&t=1987s (m.18). Ambas intervenciones recogidas en el Canal de YouTube de la Fundación Universitaria Española. «Congreso la mayor hazaña náutica de la historia: La primera circunnavegación» y en el volumen monográfico sobre el evento publicado por la Revista Cuadernos de Investigación Histórica, $n .36$.
} 
jeto de un análisis pormenorizado desde diversos ángulos tal como nos hemos propuesto en este estudio monográfico. Es realmente una mujer española que desarrolla su vida en diversas naciones europeas, con relaciones con todos los arquitectos de la Europa de su momento en que toda la diplomacia europea pasaba por Francia.

La forma de ser y de actuar de Doña Eugenia, unida a su belleza e inteligencia, en una posición social tan destacada y con una proyección internacional tan relevante en su momento, atrajo ya desde su tiempo la atención sobre su figura y la configuró como un icono para su tiempo. Sobre la extensa bibliografía que existe sobre su persona, su sobrino-nieto, el Duque de Alba, expone lo siguiente:

"Se han escrito muchos libros sobre la Emperatriz, y no dejarán de escribirse muchos más en lo sucesivo; su recia personalidad y la romántica historia de su vida interesarán siempre a los lectores. Para no mencionar sino algunos biógrafos, citaré a Sencourt, Loliée, Lucien Daudet, Aubry, Filon. y, por último, aunque no por ello menos interesante, a Dame Ethel Smythe, recientemente fallecida, que consiguió en sus escritos hacer una excelente semblanza de la Emperatriz. Por su vecindad con ella en Farnborough, llegó a ser una de sus mejores amigas: era una personalidad relevante, música distinguidísima y llegó a componer óperas de verdadera importancia que la valieron el título de «Dame»'. Fue además escritora notable: sus Memorias y Recuerdos han tenido gran éxito, contribuyendo mucho a dar a conocer la personalidad de la Emperatriz en Inglaterra. Era deportista entusiasta, y tomó con gran calor el voto de la mujer, sufriendo por ello choques con la policía y encarcelamientos. La Emperatriz veía todo esto con simpatía y la divertían mucho las extravagancias de esta dama eminente." 10

De los muchos biógrafos que se han aproximado a la vida de la Emperatriz Eugenia, el Duque cita como los más relevantes los nombres de Sencourt, Loliée, Lucien Daudet, Aubry, Filon y Dame Ethel Smythe. Quizá es oportuno recordar en este punto que estos son los autores que se mencionan en los discursos del Duque de Alba a principios de los años 40, pero el interés por la figura de la Emperatriz no solo no ha cesado en este tiempo, puesto que su figura ha seguido cautivando y atrayendo a numerosos escritores que se han aproximado a su biografía y a su circunstancia histórica posteriormente, muchos de ellos periodistas con libros muy recientes y de notable éxito editorial en nuestros días.

Puede sorprender que todos los autores que cita el Duque sean extranjeros, pero gran parte de la bibliografía, especialmente la más contrastada, especiali-

${ }^{10}$ ALBA, JACOBO FITZ-JAMES STUART Y FALCÓ, DUQUE DE, Discurso sobre la Emperatriz Eugenia en la Academia de Doctores del Distrito Universitario de Barcelona. Curso 1946-47, Diana Artes Gráficas, Madrid, 1947, pp. 13-14 
zada y rigurosa, ha sido escrita por extranjeros, si bien en español hay cada vez un mejor y más detallado conocimiento de su persona, su contexto histórico, su importancia y su significación

El Duque refiere y evalúa la amplia bibliografía existente sobre la Emperatriz hasta aquellos momentos -años 40- y destaca la que considera la mejor obra sobre su tía-abuela:

"Sigo creyendo que el mejor de todos aquellos libros es el que escribió mi amigo el profesor Sencourt, y prefiero la edición francesa porque está expurgada de los errores que se deslizaron en la inglesa primitiva y se corrigieron después." 11

Parece que la semblanza trazada por el historiador inglés Robert Sencourt, publicada bajo el título The life of the Empress Eugénie ${ }^{12}$, es la que más le convence al sobrino-nieto de la Emperatriz, aunque matiza que en su edición francesa. ${ }^{13}$ También realizó Sencourt, en relación con Doña Eugenia, una edición de las cartas personales a su hermana Francisca de Alba, publicadas bajo el título Les fiançailles de l'Impératrice: lettres a la duchesse d'Albe. ${ }^{14}$

El acreditado biógrafo Sencourt, amigo íntimo del gran poeta y dramaturgo T.S. Eliot, Premio Nobel de Literatura, sobre el que también escribe una biografía ${ }^{15}$, elabora asimismo otra sobre el marido de Doña Eugenia, el Emperador Napoleón III, bajo el título Napoleon III: The modern Emperor ${ }^{16}$. También publicó Sencourt, junto a Victor Wellesley, otra interesante obra titulada Conversations with Napoleon $\mathrm{III}^{17}$, con abundante documentación inédita referente al Emperador y al contexto histórico del II Imperio francés.

${ }^{11}$ Ibidem, p. 14

12 SENCOURT, R, The life of the Empress Eugénie. (With a Foreword by His Grace The Duke of Berwick and Alba), Charles Scribner's Sons, Nueva York, 1931.

${ }^{13}$ Idem, La vie de l'Impératrice Eugénie, Paris, Gallimard, 1933.

${ }^{14}$ MONTIJO E. DE, Les fiançailles de l'Impératrice: lettres a la duchesse d'Albe (SENCOURT, ed.) Revue des Deux Mondes (1829-1971), Huitième Oériode, vol. 10, nº 2 (15 juillet 1932), pp. 295-301. Son cartas provenientes del archivo familiar del Duque de Alba, recopiladas y editadas por Sencourt, quien durante su investigación en Madrid, encontró cartas inéditas de la emperatriz Eugenia a su hermana la Duquesa de Alba. Son cartas personales, escritas apresuradamente y sin ninguna preocupación por el estilo tal como refiere el historiador en la introducción a las mismas: “Au cours de recherches qu'il effectuait à Madrid, dans les archives de M. le duc d'Albe, un historien anglais , le très dis- tingué $M$. Robert Sencourt, a retrouvé des lettres inédites de l'impératrice Eugénie à sa soeur la duchesse d'Albe. Ces lettres familières, écrites en [hâte et sans aucun souci de style , à une soeur chérie, sont un document psychologique d'un vif intérêt, outre qu'elles révèlent des détails inconnus sur les fiançailles impériales. Nous exprimons notre gratitude à M. le duc d'Albe , qui a bien voulu donner à la Revue l'autorisation de reproduire ces lettres, ainsi que celle adressée par Napoléon III ala cofrítesse de Montijo pour lui demander la main de sa fille." MONTIJO E. DE, Les fiançailles de l'Impératrice: lettres a la duchesse d'Albe (SENCOURT, eds.) Revue des Deux Mondes (1829-1971), Huitième Oériode, vol. 10, nº 2 (15 juillet 1932), p. 295.

${ }^{15}$ Idem, T. S. Eliot, A Memoir. Londres, Garnstone Limited, 1971.

${ }^{16}$ Idem, Napoleon III: The modern Emperor, D. Appleton-Century, Nueva York, 1933.

${ }^{17}$ WELLESLEY, V. \& SENCOURT, R., Conversations with Napoleon III (a collection of documents, mostly unpublished and almost entirely diplomatic selected and arranged with introductions 
También refiere el Duque de Alba su aportación personal al conocimiento público de su tía-abuela y el sentido de la misma:

"He tenido la fortuna de contribuir a esta bibliografía de la Emperatriz con dos libros: el que inserta la copiosa correspondencia mantenida por Merimée con la Condesa de Montijo, que comenzó en 1839 y terminó con la muerte de él en 1870 (luego os diré el motivo de la publicación de estas cartas), y el aparecido con el título Lettres familieres de l'Imperatrice Eugénie, donde se contiene la correspondencia entre la Emperatriz y su madre, su hermana y su padre, y la que mantuvo con mi madre y conmigo, que abarca el período comprendido entre 1836 y su muerte, en 1920. La Emperatriz se distingue realmente en el género epistolar, y estas cartas tienen especial interés para los historiadores, porque están escritas con característica sinceridad. Este último libro, publicado en francés hace años, ha sido traducido al español e impreso en octubre de 1944 por la Editorial Gili, de Barcelona."18

El Duque deja constancia de la relevancia de las cartas personales para aproximarse al conocimiento en detalle a la vida y las relaciones de la Emperatriz Eugenia, en razón de la sinceridad con que uno se suele expresar generalmente en el género epistolar, que en el caso de su tía-abuela él estima especialmente destacada y verídica ${ }^{19}$.

Los discursos de D. Jacobo Fitz-James Stuart y Falcó, Duque de Alba, que realizó como Director de la Real Academia de la Historia en la Universidad de Barcelona en el curso 1946 - 47 y el pronunciado en The Arc, en Oxford, en 1941, revisten un gran interés por la cercanía y el conocimiento derivado de un trato familiar que él mantuvo con la Emperatriz. Además, es una relación continua en el tiempo en que transcurrió la vida de nuestra protagonista, pero que adquiere una especial relevancia cuando se tiene en cuenta que durante los últimos años de su existencia el Duque la acogió en su propia residencia.

En nuestra aproximación a la figura de Doña Eugenia nos vamos a centrar más en el discurso de Barcelona porque es posterior y viene a ser como una actualización cinco años posterior al ofrecido en Oxford. Vamos a seguir este discurso como hilo conductor de nuestra aproximación a la figura de la Emperatriz Eugenia.

Ambos discursos del Duque comienzan de una forma muy parecida, agradeciendo la invitación a hablar sobre su familiar, la Emperatriz Eugenia, tema que le es grato por el agradecimiento y el profundo cariño que la profesaba.

\footnotetext{
by Victor Wellesley and Robert Sencourt), Londres, E. Benn, 1934.

${ }^{18}$ ALBA, JACOBO FITZ-JAMES STUART Y FALCÓ, DUQUE DE, Discurso sobre la Emperatriz Eugenia en la Academia de Doctores del Distrito Universitario de Barcelona. Curso 1946-47, Diana Artes Gráficas, Madrid, 1947, pp. 14-15

${ }^{19}$ Cfr. IMPÉRATRICE EUGÉNIE (DUKE OF ALBA \& GABRIEL HANOTAUX, eds), Lettres familières de l'impératrice Eugénie, París, Plon, 1871 -1872.
} 
El Duque comienza su intervención en Barcelona refiriendo el gusto que le supone el encargo del Rector de la Universidad de Barcelona y revelando algunos detalles personales sobre su relación con la Emperatriz:

"Comienzo por daros las gracias por vuestra invitación y a la vez por haber elegido a la Emperatriz Eugenia como tema de mi conversación. Este me es agradabilísimo porque la conocí muy bien y la quise mucho. Ocupaba posición relevante en mi familia; fue como una madre para mi padre, que había perdido la suya siendo niño, y para mí más que una abuela cariñosa. Sabéis también, sin duda, que terminó, en mi casa de Madrid, su larga vida." 20

Como vemos, además de los consabidos vínculos familiares, había también motivos de profundo agradecimiento personal, por su actuación en momentos difíciles para la familia, en el trasfondo del afecto que la profesaba. D. Jacobo Fitz-James Stuart y Falcó, Duque de Alba expresa su cariño hacia Eugenia porque había sido como una madre para su padre, cuando perdió a la suya de niño, por lo que él la trató como si fuera su abuela, aunque realmente era tía-abuela suya. Tuvo una estrecha relación con Eugenia por las razones que detalla a continuación:

"Era hermana de mi abuela, la Duquesa de Alba, y cuando ésta murió, en 1860, mi padre y sus dos hermanas quedaron al cuidado de la Emperatriz, que fue para ellos la más amante de las madres. Heredé esta tradición y la consideré siempre como suplementaria abuela paterna." 21

El Duque la consideró y la trató siempre como si fuera su propia abuela, aunque realmente era tía-abuela por vía paterna. Confiesa que la profesó un gran afecto durante toda su vida, por lo que, al final de la misma, incluso la acog ó en su casa.

Parece razonable suponer que, en esos años finales, en ese declinar de la vida que es la vejez y donde se suele hacer balance de todo lo vivido, Doña Eugenia y él mantendrían largas e interesantes conversaciones. Aunque no se mencionan de forma expresa en los discursos, ni se detalla el contenido de las mismas, se puede suponer que sí tuvieron lugar a partir de las afirma iones que sí realiza el Duque sobre su tía-abuela y el afecto que le profesaba. Hay que tener en cuenta que Doña Eugenia tuvo una existencia muy longeva y alcanzó la notable edad de 94 años en una época en que la esperanza de vida para una mujer era poco más de la mitad $^{22}$. Si bien es cierto que las circunstancias de su vida no fueron ni mucho

${ }^{20}$ ALBA, JACOBO FITZ-JAMES STUART Y FALCÓ, DUQUE DE, Discurso sobre la Emperatriz Eugenia en la Academia de Doctores del Distrito Universitario de Barcelona. Curso 1946-47, Diana Artes Gráficas, Madrid, 1947, p. 7.

${ }^{21}$ Ibidem, p. 8

${ }^{22}$ Como es sabido, el aumento de la esperanza de vida se incrementó a partir de la Revolución Industrial y ascendió notablemente en los inicios del siglo XX. El alcantarillado, la higiene y los avances en la medicina, particularmente el descubrimiento de los antibióticos, son citados entre los 
menos las habituales en una mujer de su tiempo, ni en su educación, ni en sus entornos sociales, ni en sus responsabilidades.

\subsection{Etapas de la vida de Eugenia.}

Desde ese conocimiento personal derivado de un trato familiar que tuvo el Duque con la que consideraba su abuela, unido al interés por un por un conocimiento histórico de su figura, D. Jacobo establece las siguientes etapas para organizar una aproximación cronológica ordenada a la dilatada y compleja trayectoria vital de nuestra protagonista:

"La vida de Eugenia de Guzmán puede dividirse en tres períodos: el de su infancia, el de su vida de casada con el Emperador de los franceses y el de su viudez, transcurrida en el apartamiento. Procuraré daros mis impresiones personales, ilustradas con alguna que otra anécdota, más bien que referencias históricas fáciles de encontrar en cualquiera de los libros citados." ${ }^{23}$

Por lo tanto, debemos considerar tres etapas en la vida de Doña Eugenia: una primera, antes de conocer al Emperador; otra segunda, su vida junto a él y una tercera, tras su fallecimiento. Como hemos recordado, Doña Eugenia vivió hasta los 94 años, una edad inusual en su tiempo, por lo cual la tercera etapa abarca una parte muy extensa de su existencia.

Vamos a seguir el relato del Duque, fundamentalmente en el Discurso de Barcelona, contrastándolo en sus diferencias con el de Oxford y enriqueciendo su relato precisamente con referencias a los autores a los que él menciona en aquellos campos en que consideramos más relevante el sentido de su aportación para trazar una semblanza de Doña Eugenia desde esta aproximación hermenéutica a los discursos del Duque.

\section{Vida de Doña Eugenia antes de conocer al Emperador.}

\subsection{De su carácter a su linaje}

El Director de la Real Academia, recuerda sus impresiones del primer encuentro con su tía-abuela en Bruselas:

factores que más incidencia tuvieron en el aumento de la esperanza de vida. Doña Eugenia fallece en 1920 que es la época en que empieza el gran desarrollo de los antibióticos, especialmente tras la I Guerra Mundial.

${ }^{23}$ ALBA, JACOBO FITZ-JAMES STUART Y FALCÓ, DUQUE DE, Discurso sobre la Emperatriz Eugenia en la Academia de Doctores del Distrito Universitario de Barcelona. Curso 1946-47, Diana Artes Gráficas, Madrid, 1947, p. 1 
"La primera vez que la vi, tenía yo seis o siete años. Había ido ella a Bruselas, adonde me condujeron a mí con mis hermanos para saludarla, y desde que, a los catorce años, fui al Colegio de Beaumont, junto a su casa de Farnborough, donde ella residía y donde había construido el panteón del Emperador y del Príncipe, hasta el día de su muerte, no hubo año en que no pasara a su lado un par de meses, bien en Inglaterra, bien en Cap Martin, su casa de recreo del Mediodía de Francia. Vino además varias veces a España, donde murió a los noventa y cuatro años en circunstancias que os relataré después." ${ }^{24}$

Tras aquel primer encuentro en Bruselas, el Duque se vio con la que consideraba su abuela, en Farnborough, en el condado de Hampshire, en Inglaterra, con cierta asiduidad, porque él estudiaba en un colegio ubicado en las cercanías. También se vieron en Francia, especialmente en épocas de vacaciones, y finalmente, también en España, donde el propio sobrino-nieto la acogió en su casa hasta el fin de sus días, porque Doña Eugenia vivió, cabe recordar, hasta la inusual edad en su tiempo de 94 años.

Sobre el carácter de Doña Eugenia, su sobrino-nieto recuerda los principales rasgos de su forma de ser. En este sentido destaca que:

"Como todos los seres humanos, tenía cualidades y defectos; pero, en mi opinión, las primeras sobrepujaban considerablemente a los segundos, y en todo caso puedo afirmar que poseía en alto grado dos grandes virtudes: el valor personal y un agudísimo sentido del honor. Ambas cualidades son típicamente españolas y procuró siempre conservarlas." 25

De su carácter subraya que sobresalían dos cualidades: el valor personal y el sentido del honor, que el Duque atribuye inequívocamente a su origen español. Puede resultar llamativa en la actualidad la adscripción que hace el Duque de tales virtudes al origen español de Doña Eugenia. ¿Es una mera cuestión de patriotismo en el contexto de posguerra?

En el señalamiento de estas dos virtudes como típicamente españolas, creemos que tenemos que tener presente que estamos ante un personaje histórico del contexto de la Guerra de Independencia donde personajes anónimos del pueblo español mostraron la bravura de su carácter y el arrojo de enfrentarse a la que era, en aquellos momentos, la primera potencia del mundo liderada por Napoleón Bonaparte.

En un contexto de enfrentamiento bélico absolutamente desigual, personajes anónimos del pueblo español se convirtieron en grandes héroes nacionales por circunstancias sobrevenidas que dieron ocasión para mostrar su arrojo ante un

\footnotetext{
${ }^{24}$ Ibidem, p. 9

${ }^{25}$ Ibidem.
} 
invasor extranjero. Parece lógico que, derivado de aquel contexto histórico tan dramático, en que hubo ocasión para mostrar tales cualidades -que es preciso recordar que no se dieron en otros lugares de Europa ante circunstancias análogas $^{26}$-, se asocie la virtud del valor con el carácter español más allá de lo que un sentimiento patriótico pueda comportar.

Sobre los orígenes familiares de la que sería Emperatriz de Francia, el Duque de Alba recordaba que Doña Eugenia:

"Nació en Granada el 11 de mayo de 1826, entre tormentas y terremotos. Su padre era aristócrata de sangre azul, el Conde de Montijo y de Miranda, que fue también Duque de Peñaranda y tuvo otros títulos."27

Lo de los terremotos que acontecieron en fechas próximas a su nacimiento, eventos que contribuyeron a realzar la leyenda sobre su persona en el imaginario popular, es una cuestión que todavía hoy se discute. Aunque no es descartable que así fuera, porque, Granada está ubicada en una zona de actividad sísmica bastante propensa a sufrir seísmos de relativa intensidad cada cierto tiempo.

Sobre el padre de Doña Eugenia, su sobrino-nieto expone lo siguiente:

"Como Conde de Montijo sucedió a su hermano, famoso personaje de aquel tiempo, apodado «el tío Pedro», que había intervenido en las agitaciones políticas de su época. Por raro caso entre los nobles españoles de aquel tiempo, el Conde de Montijo era un afrancesado que había servido la causa de Napoleón como oficia de artillería, y antes se había roto una pierna en el Puerto de Santa María frente a los ingleses, y sufrido la pérdida del ojo derecho por el reventón de un fusil en el probadero de la Maestranza de Sevilla. En 1814, capitaneando a los estudiantes de la Politécnica, fue uno de los últimos defensores de las alturas de Montmartre, contra los ataques de los ejércitos aliados, muy poco antes del derrumbamiento de la causa napoleónica. No sospechaba entonces que la hija a quien tanto quería (como advertimos por las cartas que ella le escribió siendo niña ), había de casarse con

\footnotetext{
${ }^{26}$ Acaso sea oportuno referir sobre esta peculiaridad de la bravura exhibida por personajes anónimos del pueblo español ante la invasión francesa napoleónica durante la Guerra de Independencia que en la mayoría de las lenguas quedó recogida y manifiesta en una palabra de origen español derivada de la forma de enfrentamiento a que dio lugar la desigualdad entre las partes contendientes. Nos referimos, evidentemente, a la palabra guerrilla. Palabra de origen español, acuñada en esta época y que existe en todos los idiomas, aunque pronunciada de forma diversa. En la tercera acepción contemplada en el Diccionario de la Real Academia el término queda recogido en esta acepción en un sentidocomo "partida de paisanos, por lo común no muy numerosa, que al mando de un jefe particulart y con poca o ninguna dependencia de los del Ejército, acosa y molesta al enemigo" se recoge esta forma de enfrentamiento en condiciones desiguales que presupone indefectiblemente el valor personal." RAE, Diccionario Lengua Española (DEL). Disponible en https://dle.rae.es/guerrilla

${ }^{27}$ ALBA, JACOBO FITZ-JAMES STUART Y FALCÓ, DUQUE DE, Discurso sobre la Emperatriz Eugenia en la Academia de Doctores del Distrito Universitario de Barcelona. Curso 1946-47, Diana Artes Gráficas, Madrid, 1947, p. 1
} 
el heredero de aquel gran Napoleón, por el que sintió durante toda su existencia admiración tan profunda." 28

Sobre la condición de «afrancesado» del Conde de Montijo, en el discurso de Oxford emplea además el término de francófilo $^{29}$, aparentemente contradictoria con su condición aristocrática, especialmente cuando consideramos que la Revolución Francesa había significado un movimiento contrario a los derechos de los estamentos privilegiados, entre los que desde luego se incluían en lugar preferente los de la aristocracia, conviene precisar que no fue una circunstancia tan infrecuente entre la nobleza española como pudiera pensarse. Tal como oportunamente explicaba Julián Marías sobre aquella época:

"Una porción considerable de las minorías ilustradas cree que la potencia de Napoleón es incontenible y hay que obrar en consecuencia; es decir, aceptarla y colaborar para seguir adelante. Muchos de estos hombres eran nobles y bien intencionados; habían puesto sus admiraciones y su esperanza en Francia, y pesar de todo le concedían crédito; veían por otra parte, la vileza en que había caído el «antiguo régimen», que les parecía inferior. Con ciertas reservas y repugnancias, creen que no hay más salida que aceptar los hechos consumados, tratar de que la ocupación sea benigna, emprender una nueva trayectoria inspirada por la Francia napoleónica, en la cual creen ver el espíritu de la Revolución. Estos fueron los «afrancesados», con diversos matices, que van de lo estimable a lo oportunista." ${ }^{.30}$

Más allá del hecho de la invasión de España, con la flagrante violación de la soberanía nacional que condujo al levantamiento popular, del carácter revolucionario y disruptivo que comportaban las ideas francesas en aquel tiempo o de la admiración por la figura de Napoleón Bonaparte, la adscripción a la causa francesa en la época realmente tuvo también otras connotaciones culturales y políticas ilustradas, que son subrayadas por Marías.

El afrancesamiento significó en España también la irrupción de un espíritu liberal y reformista frente al tradicional inmovilismo, el atraso social o la desconfianza arraigada frente a todo lo extranjero. Por lo tanto, no es tan de extrañar -como apunta Marías- que al menos una parte de la aristocracia nacional simpatizase con ese espíritu reformista que comportaba la causa francesa y que evidentemente no pudo calar de forma mayoritaria en el conjunto de la población española, sino solo en una minoría ilustrada muy limitada.

\footnotetext{
${ }^{28}$ Ibidem.

${ }^{29}$ Idem, La Emperatriz Eugenia / el Duque de Alba: Conferencia pronunciada en «The Ark», Oxford, 15 de julio de 1941, Biblioteca Virtual Miguel de Cervantes, Alicante, 2012, p. 199. Disponible en http://www.cervantesvirtual.com/obra/la-emperatriz-eugenia/

${ }^{30}$ MARÍAS AGUILERA, J., España inteligible. Razón histórica de las Españas, Alianza Editorial, Madrid, 2014, pp. $318-319$.
} 
Por otra parte, la injerencia transnacional y la violencia de la irrupción francesa en la soberanía nacional es lógico que generase un sentimiento inicial de resistencia que se tornó en abierta oposición y rechazo entre la mayoría de la población española, no solo al ejército invasor, sino al conjunto de influencias que pudieran asociarse a la causa francesa, con independencia de que fueran buenas o malas, lo cual no podía ser objeto de un análisis muy sosegado, por otra parte, en tan dramáticas circunstancias.

Aunque la división del pueblo español ante el influjo francés, condujo -según Marías- a una tendencia a la radicalización de las posiciones y a la generación de una simiente de enfrentamiento nacional y discordia entre los españoles, que lejos de atenuarse, se asentaría e incluso se acrecentaría con el tiempo. En el transcurso de la historia posterior, recurrentemente, ese espíritu de discordia se encendería en distintas ocasiones, generando enfrentamientos viscerales entre los españoles que mostraron su cara más visible en las diversas guerras nacionales que se sucedieron durante los siglos XIX y XX. Cabe recordar que, en uno de esos episodios de enfrentamiento nacional, durante las guerras carlistas, la propia Eugenia fue llevada a Francia.

En sus discursos el Duque destaca que Doña Eugenia provenía de un linaje emparentado con héroes de la defensa de la nación en distintos momentos de la historia de España.

En el discurso de Oxford, el Duque se remonta a los antecedentes familiares de Doña Eugenia hasta el tiempo de la Reconquista con una circunstancia histórica muy ilustrativa:

"Pertenecía a la familia de los Guzmanes, descendiendo, por tanto, de aquel famoso Alonso Pérez de Guzmán, apellidado «El Bueno», considerado en España como modelo de caballeros leales. Gobernaba el Castillo de Tarifa, sitiado por los moros en el siglo XIII. Los sitiadores tenían cautivo a su hijo, y llevándole al pie de las murallas, amenazaron con la muerte del niño si Guzmán no se rendía. Su contestación fué sacar el puñal de su vaina y lanzarlo a los enemigos, gritando: «Podéis matar a mi hijo, pero no conseguiréis que traicione mi causa.» Como sabéis, este noble ademán ha sido renovado hace bien poco por el Coronel Moscardó, defensor del Alcázar de Toledo." ${ }^{11}$

En la alusión al antepasado de Doña Eugenia, el Duque realza la determinación en el cumplimiento de sus obligaciones y la lealtad incondicional a la causa cristiana, cualquiera que sea el precio a pagar en el ámbito personal o familiar. Relaciona esa determinación con la actitud exhibida por el Coronel Moscardó en

${ }^{31}$ Idem, La Emperatriz Eugenia / el Duque de Alba: Conferencia pronunciada en «The Ark», Oxford, 15 de julio de 1941, Biblioteca Virtual Miguel de Cervantes, Alicante, 2012, p. 199. Disponible en http://www.cervantesvirtual.com/obra/la-emperatriz-eugenia/ 
la defensa del Alcázar de Toledo. Esta segunda alusión debe comprenderse en el contexto de la posguerra del año 1941 en que se realiza este discurso, que ya no aparece en el de Barcelona.

En el discurso de Barcelona, es más escueto al referir los antecedentes familiares de Eugenia, centrándose más en los más próximos:

"Aunque la Emperatriz se apellidaba Palafox por su padre, nombre notorio en la heroica defensa de Zaragoza durante la guerra de la Independencia, hubo de cambiar, como era entonces costumbre, este apellido al heredar de su padre algunos Mayorazgos que la correspondían, y como algunos de éstos requerían el nombre de Guzmán, se llamó Eugenia de Guzmán. Descendía, en efecto, por los Mayorazgos de Teba y Ardales, del famoso Alonso Pérez de Guzmán el Bueno, héroe del conocido episodio del sitio de Tarifa." 32

La asociación del nombre de Eugenia de Montijo, por razones de linaje, con grandes héroes nacionales de la Guerra de Independencia parece una clara alusión compensatoria por parte del Duque a la antes referida adscripción de su padre al bando francés durante el conflicto bélico con la nación gala, especialmente en el contexto de la postguerra, en los años 40, en que son pronunciados los discursos. Ahora bien, si por motivos de linaje se legitiman o no las adscripciones a un bando en un conflicto bélico, cuánto más las actuaciones personales, es algo que dejamos a la conciencia de cada cual juzgar.

Sea como fuere, el Duque justifica la modificación de algunos de estos apellidos de renombre de Doña Eugenia por razones de herencia, lo cual, era, ciertamente, una costumbre usual en la época, especialmente entre las personas con un linaje aristocrático como era el caso de su tía-abuela.

En lo familiar, la infancia de Doña Eugenia y de su hermana Paca estuvo marcada por la temprana muerte de su padre y el esfuerzo de su madre por darlas una educación acorde a su status. Sobre la madre de Eugenia, el Duque expone que:

"El Conde de Montijo falleció cuando sus dos hijas eran muy jóvenes, quedando ellas encomendadas a la madre, que vivió muchos años, porque murió de ochenta y cinco, en 1879. Esta señora fue persona realmente extraordinaria; tenía origen escocés, el de la famila Kirkpatrick de Closeburn, muy perseguida por su devoción a la causa de los Estuardos. Su padre había emigrado a Málaga, donde alcanzó gran prosperidad y llegó a ser Cónsul americano. Era hermosísima, como se advierte en sus retratos, pero todavía superaban a su hermosura las cualidades de su entendimiento y de su carácter." ${ }^{\text {33 }}$

\footnotetext{
${ }^{32}$ ALBA, JACOBO FITZ-JAMES STUART Y FALCÓ, DUQUE DE, Discurso sobre la Emperatriz Eugenia en la Academia de Doctores del Distrito Universitario de Barcelona. Curso 1946-47, Diana Artes Gráficas, Madrid, 1947, pp. 10 - 1.

${ }^{33}$ Ibidem, p.11
} 
En nuestra investigación hemos contactado con algunos miembros de la familia Kirkpatrick, afincados en Madrid y que amablemente nos han ofrecido acceso al archivo familiar para la consulta y verificación de documentos que han permitido cotejar algunos detalles y circunstancias referidas en el presente trabajo, así como retratos y fotografías familiares y libros sobre la Condesa de Tebas.

El atractivo de Doña Eugenia no estribaba solo, ni principalmente, en su belleza física, que también la tenía y mucha -como se evidencia en los numerosos retratos que la inmortalizaron-, sino en el encanto de su personalidad, de su fino entendimiento y su carácter, que irradiaba en los distintos círculos sociales en que se movía, según testimonio del Duque.

\subsection{De su posición internacional}

Doña Eugenia se desenvolvía con solvencia en los distintos ambientes y circunstancias, siempre en una posición de referencia. En sus discursos, el Duque de Alba refiere la destacada posición que ocupaba Eugenia en los distintos lugares -Madrid, París, Londres- en que se encontrase:

"La Condesa de Montijo ocupaba una situación excepcional en el gran mundo de su tiempo, no sólo en Madrid, sino en París, en Londres y dondequiera que viviese. En Madrid era figura relevante de la buena sociedad. Su palacio de la plaza del Ángel, que después fue Casino Militar, y su casa de recreo de Carabanchel, en los alrededores de la capital, eran centro de reunión de las personalidades contemporáneas más destacadas: políticos, generales, escritores, pintores, poetas, todos eran allí bien recibidos." ${ }^{.34}$

En el entorno social que traza su sobrino-nieto en torno a ella, siempre la sitúa rodeada de personalidades relevantes de su tiempo: políticos, generales, escritores, pintores, poetas, por lo que es evidente que tenía una gran facilidad para desenvolverse con solvencia y facilidad en las relaciones sociales.

En el sentido cultural, cabe destacar que Eugenia va a mantener una relación personal y epistolar con importantes escritores y personajes de la cultura europea de su tiempo. Así la refiere el Duque en sus discursos

"Me limitaré a citar a Próspero Merimée, el delicioso escritor, sincero amigo suyo, quien, bajo la máscara de un escepticismo casi cínico, ocultaba un noble y ardiente corazón. Esta amistad ha quedado consagrada en muchas cartas suyas a la Condesa, que yo he tenido la satisfacción de publicar. Ella fue quien le contó la leyenda de Carmen, argumento de la novela de Merimée, origen del libreto escrito

\footnotetext{
${ }^{34}$ Ibidem, p. 12
} 
por Meilhac y Halevy para la famosa ópera del músico Bizet. Stendhal. Serrano, Narváez, Washington Irving, así españoles como extranjeros, rendían homenaje a la excepcional inteligencia de esta señora notabilísima." ${ }^{35}$

La nómina de autores, escritores y compositores citada por su sobrino-nieto en el círculo de relaciones personales de Doña Eugenia es realmente relevante y significativa, especialmente para una mujer de su status social. Lo cual, evidencia que por sí mismo, que algo más tendría que belleza y posición para granjearse el aprecio de un círculo de intelectuales y escritores tan selectos.

También refiere el Duque alguna anécdota personal para ilustrar el carácter y el ingenio de Doña Eugenia ante algunas inconveniencias de los selectos círculos sociales en que se movía. Expone el Duque:

"Permitidme que os ofrezca un rasgo de su ingenio: poco después de casar su hija con el Emperador de los franceses, acontecimiento que era a la sazón tema de actualidad, se le acercó una princesa de la Casa de Borbón y la espetó esta inconveniencia:

«He oído decir que una hija de usted se ha casado hace poco'», a lo que contestó con aguda rapidez: «Sí, señora, está viviendo en las habitaciones que ocupó últimamente la madre de V. A.»»"36

La agudeza y el ingenio de la respuesta de Doña Eugenia no es menos de destacar que la rapidez y concisión con que -sin faltarle al respeto- le hace reflexionar a esta princesa sobre su propia condición debida a la posición adquirida por su madre.

\subsection{De la circunstancia española a su marcha a Francia.}

En un contexto de dificultades y enfrentamientos en España, Doña Eugenia será llevada a Francia, donde recibirá su educación:

"Sus primeros años coincidieron con una constante agitación y una guerra civil en España. (...) Por este tiempo fue llevada Eugenia a París para educarse en el Colegio del Sagrado Corazón. El viaje era largo y además hubo de hacerse con gran rodeo, porque el camino normal a través de la frontera vasca estaba ocupado por los carlistas. Todas estas aventuras impresionaron mucho su juvenil imaginación. Llegó a París con su hermana y con su madre, y allí fue donde, merced a la afición de ésta por cultivar la amistad de hombres excepcionales, trató a Merirnee y a Beyle, más conocido por su seudónimo de «Stendhal». Este jugó con ella y la

\footnotetext{
${ }^{35}$ Ibidem.

${ }^{36}$ Ibidem, pp.12-13.
} 
contó historias que fascinaron su imaginación, referentes, sobre todo, a las guerras napoleónicas, en las que había tornad o parte." ${ }^{\text {37 }}$

El siglo XIX, como es bien sabido, conoció una secuencia de enfrentamientos civiles en España, las denominadas las Guerras carlistas, que se iniciaron por cuestiones sucesorias de acceso al trono español, pero derivaron en una confrontación de otra naturaleza, más bien ideológica e identitaria, en que la que también se incluía la cuestión sucesoria. El carlismo fue un movimiento tradicionalista español, que bajo el lema «Dios, Patria y Rey» defendió las tradiciones, las instituciones y la fe católica frente a las ideas liberales, la secularización y las reformas legales y sociales.

Tales circunstancias bélicas motivaron la salida de España de Doña Eugenia. Si bien, tras el fallecimiento de su padre, habría de volver nuevamente a España, a Madrid, donde viviría algunos romances en su juventud. Así lo relata el Duque:

"Pocos años después, al fallecer su padre, ella y su hermana volvieron a España, donde la vida les fue muy agradable. La residencia de Carabanchel era el centro de toda la juventud del día y la reunión de las muchachas y muchachos de su tiempo. Dado el temperamento de Eugenia, se enamoró pronto, y el hombre que la inspiró su primera pasión fue el Duque de Alba, mi abuelo. Debo advertir que las dos hermanas eran guapísimas; mi abuela era morena, mientras que la Emperatriz era rubia, más bien roja. Accidentalmente la oí decir que durante su niñez se avergonzaba de tener el pelo tan rojo; lo consideraba entonces como una gran desgracia, y la sorprendió mucho, cuando llegó al trono, que esa cualidad constituyese la última palabra de la moda en Francia." 38

El Duque enfatiza el carácter enamoradizo de Doña Eugenia y el detalle del cabello pelirrojo de Condesa de Teba, que para ella debió suponer un cierto complejo de su estética personal, pero dada la relevancia social y el carácter icónico de su figura, instauraría una novedosa moda entre las mujeres francesas cuando ella llegó al trono de Francia. En lo estético, como hemos dicho, fue siempre una mujer icónica y creadora de estilo. Ella misma se sorprendía -y según testimonio de su sobrino-nieto- se reía de esa capacidad de influenciar el gusto estético de su tiempo.

Ambas hermanas, Doña Eugenia y Doña Francisca, tuvieron mucho éxito en su juventud debido a su belleza. En sus discursos, el Duque refiere el interés que ambas hermanas despertaron entre los jóvenes de su época, al que no fue ajeno su propio abuelo:

\footnotetext{
${ }^{37}$ Ibidem, p. 16

${ }^{38}$ Ibidem, pp.16-17.
} 
"Los afectos de muchos jóvenes de la época titubearon ante la opción entre las dos encantadoras hermanas. Mi abuelo, que probablemente galanteó a las dos, acabó decidiéndose por mi abuela y ello fue un tremendo golpe para Eugenia, que no contaba sino diecisiete años. Le escribió una carta, publicada luego por mí, en que dice que considera terminada su vida y que, o se retiraría a un convento o se suicidaría; y fue esto lo que trató de hacer, ingiriendo una infusión de cabezas de fósforo. Esta carta ha sido objeto de diversos comentarios, y hay quien la cree dirigida al Marqués de Alcañices; pero me parece plenamente probado que está destinada a mi abuelo, porque los amoríos con Alcañices comenzaron bastante tiempo después." 39

El gran amor de juventud de Doña Eugenia fue el abuelo del Duque de Alba. Tal como refiere su sobrino-nieto, su abuelo trató a las dos hermanas, si bien éste se decidió a declararse, formalizar la relación, y finalmente, a contraer matrimonio, con su hermana Francisca, conocida como Paca de Alba, con la consiguiente decepción de Doña Eugenia.

El Duque refiere la decepción que le supuso a Doña Eugenia el que su abuelo se decidiese por su hermana y no por ella, y cómo trato de superar la profunda decepción amorosa:

"A pesar de este choque nunca se enturbió el cariño de Eugenia hacia su hermana, ni siquiera el afecto al marido de ésta. Buscó consuelo para este desengaño dedicándose con gran entusiasmo al deporte. Había sido siempre excelente amazona y emprendió ahora grandes excursiones a caballo. Hay un cuadro suyo de este período de su vida que ha sido reproducido y que yo conservo. El pintor Odier, no gran artista, la representa montando una jaca española con romántico fondo de paisaje lleno de rocas. También fue aficionada al arte de la pintura; hizo algunas acuarelas, que, asimismo, he reproducido yo, y una de las cuales figuró en la última Exposición celebrada en Madrid." ${ }^{40}$

Si en la contrariedad y, especialmente, en el desamor se comprueba la pasta de que la que están hechas las personas, Doña Eugenia superó esa profunda decepción de la mejor manera posible: volcándose en sus hobbies del deporte y del arte. Porque, tal como refiere el Duque, Doña Eugenia tenía sensibilidad estética e interés por el arte, inclusive pintó algunas acuarelas que se atrevió a exponer públicamente.

Por otro lado, no dejó de tener muchos admiradores que la cortejaron en esa etapa, uno de los principales el Marqués de Alcañices, sobre el que expone el Duque:

\footnotetext{
${ }^{39}$ Ibidem, pp. 17-18.

${ }^{40}$ Ibidem, p. 18
} 
"No se decidió Eugenia a casarse con ninguno de los muchos jóvenes aceptables que con insistencia la cortejaban; pasó el tiempo en continuos viajes entre Francia, Inglaterra y España, y donde quiera tuvo admiradores. Uno de ellos fue el Marqués de Alcañices, a quien me he referido anteriormente. Él la tenía gran afecto, pero no se decidió nunca a declararse, intimidado, quizá, por el dominante impulso de su temperamento." 41

Quizá de todos los pretendientes españoles el más notable fue el Marqués de Alcañices, si bien tampoco se decidió a declararse y a iniciar una relación formal con Doña Eugenia, por lo que todo se quedó en una bonita relación personal.

\section{Vida de Doña Eugenia de Montijo como Empera triz.}

\subsection{Del encuentro al matrimonio imperial.}

En Francia en esos momentos se vivían momentos de gran incertidumbre que permitían vislumbrar importantes cambios políticos en el horizonte. El Duque describe el contexto político de inestabilidad que se vivía en la nación gala y las connotaciones requeridas por un nuevo régimen:

\footnotetext{
"Sobrevinieron entonces en Francia radicales cambios políticos. Napoleón Bonaparte, después de una larga cautividad y de tres intentos fracasados para adueñarse del poder, fue elegido Príncipe Presidente, y en 2 de diciembre de 1851 dio el golpe de Estado que le permitió proclamarse Emperador con el lema: «El Imperio es la paz». En la sociedad de París de aquellos días trató, como era lógico, a la Condesa de Montijo y a sus hijas, y quedó fascinado ante la extraordinaria belleza y sutil inteligencia de Eugenia. Siendo ella niña había ya visto a Napoleón cuando le llevaban preso a la Conserjería. Él era muy accesible a los encantos femeninos, y no dejó de impresionarle la gracia y el aire señoril de Eugenia de Guzmán, que llevaba entonces el título de Condesa de Teba." ${ }^{42}$
}

La necesidad de un nuevo régimen político propiciado por el contexto de inestabilidad que vivía la nación gala llevó a buscar en el pasado próximo el referente político necesario. Se asoció así la reinstauración del Imperio con un periodo de paz y estabilidad que eran deseadas por la mayoría y serían circunstancias propiciatorias del advenimiento de ese nuevo régimen encabezado por un heredero directo de aquel legado. Se añadía además la circunstancia de un gran parecido físico de Carlos Luis Napoleón Bonaparte con la figura de

\footnotetext{
${ }^{41}$ Ibidem.

${ }^{42}$ Ibidem, p. 19
} 
su tío, hermano de su padre, el conocido general y estadista francés Napoleón Bonaparte I.

En ese contexto político, se produjo el encuentro en la alta sociedad parisina entre la Condesa de Teba y el candidato a regir los destinos de la nación gala. Al parecer quedó cautivado por la aristócrata española desde aquel encuentro en que se conocieron.

El Duque refiere el carácter enamoradizo de Carlos Luis Napoleón, futuro Napoleón III, y el atractivo de la Condesa de Teba, pero se dan otras circunstancias y cualidades que conviene precisar. Sobre el atractivo de Doña Eugenia y sus cualidades para enamorar al futuro Emperador, expone Sencourt lo siguiente:

"She was a moral woman, yet like Hortense she knew how to play upon the hearts of men. (...) And it was not alone the incomparable slope of the daughter's shoulders, or the ripening of her breast, which won the Emperor. Beneath the red gold of her hair (and the rose she often placed in her curls made them particularly coquettish), the dress of Doña Eugenia was faultless in its taste, and her features showed the fineness of her race

$$
\begin{aligned}
& \text { In all her beauty, and sunlight to it } \\
& \text { is a pit, den, darkness. } \\
& \text { Foam failing is not fresh to it, rainbow } \\
& \text { by it is not beaming. } \\
& \text { In all her body, I say, no place was } \\
& \text { like her eyes. }
\end{aligned}
$$

Those deep blue eyes sparkled, as she spoke, like the Mediterranean in a breeze, but in spite of her radiant health and of the gracious curves of her figure their expression was often sad." ${ }^{23}$

Doña Eugenia combinaba unos ojos de un azul profundo e insondable, que recordaban a la brisa del Mediterráneo mientras hablaba, con un aspecto general muy saludable y una mirada triste.

Su sobrino-nieto, el Duque de Alba, recuerda sobre el encuentro de Doña Eugenia con el Emperador un episodio muy reproducido de su vida:

"Circula una anécdota, que no creo exacta, pero que entraña una realidad. Se celebraba una revista en la plaza del Carroussel; la Condesa de Montijo y su hija habían sido invitadas a presenciarla desde una ventana del palacio de las Tullerías. Terminada la revista, el Emperador, montado aún a caballo, se colocó debajo de la ventana y preguntó a Eugenia: «¿Cómo se puede llegar hasta ahí?». La leyenda supone que ella contestó: «Pasando por la capilla». En

\footnotetext{
${ }^{43}$ SENCOURT, R., Napoleon III: The modern Emperor, D. Appleton-Century, Nueva York, 1933, p. 141. pp. $139-140$.
} 
todo caso es positivo que el Emperador comprendió muy pronto que no podía satisfacer su pasión sino mediante el matrimonio. Tenía el Emperador cuarenta y siete años y, como era lógico, deseaba fundar una dinastía. Había buscado la posible alianza con alguna de las Princesas europeas, y aun cuando muchas familias reales seguían considerándole como un advenedizo, el nimbo de gloria que rodeaba su apellido y aun su persona, como Emperador de los franceses, hacía de él un gran partido." ${ }^{44}$

Fuera exacta o no la anécdota tan conocida y reproducida -sobre la que el Duque no se pronuncia- y fuera exacta o no la respuesta de su protagonista -sobre cuya literalidad tampoco se pronuncia -; lo que sí trasluce la declaración del Duque es el sentido de lo que Doña Eugenia realmente requirió al Emperador, que es contraer matrimonio formalmente ante Dios, elevando su enlace matrimonial a la dignidad sacramental que la congruencia con su fe cristiana le exigía.

Sencourt traza una semblanza donde detalla muchas de las cualidades que Doña Eugenia reunía para ser la esposa y Emperatriz consorte de Napoleón III:

"Fate was singularly indulgent to his passion when she placed in his way so superb a creature as the Empress Eugénie. Born of a family so noble as the kinsmen of kings, thrice a grande d'Espagne of the the first class, Doña Eugenia enjoyed in her own right as a younger daughter the titles of Countess de Teba an Marchioness de Moya. But her education had been peculiarly modern. Brought in loyalty to the Bonapartes, she had been form childhood a believer in social reform, even to an extreme degree. She had been taken as a child to Paris, and received he education in one of the smartest of Paris convents, while her private tutors, Mermée and Stendhal, had been two of the greatest masters of French who ever wrote romances. She spoke and wrote French, if not faultlessly, very finel, with a striking power of charming and picturesque imagery. She had been at school in England, and she had grown up intimate with an ancient court, and cognizant even at an early age of the political intrigues of which it was the centre. She had been presented at Buckingham Palace. She was a gymnast, with a supple body trained to endurance. And she had all the social arts of a woman of the world." 45

No fue un enlace exento de muchas dificultades antes del casamiento, por las numerosas pretendientes del Emperador y los compromisos de ella. El Duque de Alba refiere así las diversas dificultades existentes para hacer posible el enlace con Napoleón III:

\footnotetext{
${ }^{44}$ ALBA, JACOBO FITZ-JAMES STUART Y FALCÓ, DUQUE DE, Discurso sobre la Emperatriz Eugenia en la Academia de Doctores del Distrito Universitario de Barcelona. Curso 1946-47, Diana Artes Gráficas, Madrid, 1947, pp. 19-20

${ }^{45}$ SENCOURT, R., Napoleon III: The modern Emperor, D. Appleton-Century, Nueva York, 1933, pp. 138-139.
} 
"Su prima Matilde aspiraba muy señaladamente a este matrimonio, pero estaba casada con el Príncipe Demidolf y el Papa negaba la disolución de este vínculo. También aparecía en candidatura la Princesa Adelaida Hohenlohe, emparentada con la Reina Victoria, que no se hubiera opuesto al matrimonio; pero el Emperador se había enamorado de Eugenia y estaba dispuesto a casarse con ella. No le ocultó la Condesa de Teba tener puestos sus afectos en persona determinada, por lo cual no le daría respuesta terminante hasta estar segura de no poder casarse con el Marqués de Alcañices. Envió a éste entonces un telegrama comunicándole que el Emperador se le había declarado. La contestación fue: «Recibe mi más cordial felicitación»; señal evidente de que estaba resuelto a no casarse con ella. El telegrama de Eugenia fue interceptado por la policía y mostrado al Emperador, porque eran muchos los adversarios de este matrimonio con una extranjera que ni aun tenía sangre real; pero el Emperador contestó que estaba perfectamente enterado del asunto; y, puestas de acuerdo ambas partes, se celebró la boda."46

La condición de extranjera y la españolidad de Doña Eugenia surgía como una inconveniencia más en su vida al ir a formalizar su compromiso matrimonial. Es una circunstancia a la que debería acostumbrarse Condesa de Teba, puesto que se repetiría muchas veces en su vida, especialmente en los momentos de dificultad o tras decisiones que pudieran considerarse erróneas

Sencourt detalla las circunstancias en las que se produjo el compromiso matrimonial entre Doña Eugenia y Napoleón III y algunas de las inconveniencias que la prometida tuvo que padecer en alguna recepción oficia, por su ser la persona elegida por el Emperador para compartir su vida, de nuevo aduciendo su nacionalidad española y su condición de extranjera como motivo para cuestionar su idoneidad y descalificarla. Así lo expone Sencourt:

“ $(\ldots)$ on $14^{\text {th }}$ January, at a reception at the Tulleries, a certain Madame Fortoul pushed past the Spanish Countess with insulting words about the prominence given to a questionable foreigner. The Emperor saw that his love was furious. Tomorrow, he said, no one shall dare to insult you. After all he had placed in a vulnerable position: only in one way could he repair the harm he had done to the woman he had done to the woman he had come to worship. Next morning the Countess of Montijo had in her hands a written proposal of marriage. And so passionate was the Emperor's suit that in a fortnight form that date, Doña Eugenia de Guzman had been married to him in Notre-Dame, and reigned in France as sovereign., ${ }^{27}$

El rechazo de algunas pretendientes hacia su prometida y los comentarios inapropiados sobre ella y a ella misma, casi estimularon la determinación del Empera-

\footnotetext{
${ }^{46}$ Ibidem, pp.20-21.

${ }^{47}$ Ibidem.
} 
dor a contraer matrimonio con Doña Eugenia a la mayor brevedad posible, para despejar las habladurías y, consumando su unión, ahorrarle a su prometida nuevas inconveniencias durante el periodo previo al enlace matrimonial.

Una vez realizada la boda, Doña Eugenia aprovechó el generoso regalo del pueblo de París para hacer gala de sus virtudes cristianas y practicar la caridad con los más pobres. Sobre el enlace matrimonial, tal como refie e el Duque:

"El matrimonio fue una fastuosa ceremonia, y la Emperatriz se hizo popularísima en Francia, negándose a recibir los 600.000 francos ofrecidos por la villa de París para que se comprase una alhaja, por preferir que ese dinero se entregase a los pobres." 48

Se sabe que una gran parte de la población de París contribuyó a la cuestación popular para el regalo de la Emperatriz. Doña Eugenia tuvo la deferencia de agradecer el obsequio y donar ese dinero para obras de caridad que redundasen en beneficio de su propio pueblo. Fue un gesto que le valió una inmensa popularidad que supo apreciar el buen gesto de su nueva soberana. Pero, este acto no fue un gesto de cara a la galería, para ganarse el favor popular. Tal como señalaba Sencourt, su fe católica la impulsó siempre, incluso en el ámbito privado, hacia la caridad hacia los más pobres y desfavorecidos ${ }^{49}$, si bien sus gestos públicos como Emperatriz tuvieron gran visibilidad y repercusión social.

El nuevo status como Emperatriz supuso, además, nuevas responsabilidades y una ampliación del círculo de relaciones sociales en la vida de Eugenia, que esta supo desempeñar con gran naturalidad:

"Dos años después la pareja imperial fue a Inglaterra a visitar a la Reina Victoria. Las relaciones entre ésta y la Emperatriz se convirtieron entonces en amistad tan duradera y cordial que sólo terminó con la muerte de la Reina de Inglaterra." ${ }^{~} 50$

Su educación en Inglaterra, el hecho de haber sido ya presentada en Buckingham Palace anteriormente, unido a su cordialidad y encanto personales, contribuyeron al establecimiento de una fructífera relación con Inglaterra y una verdadera amistad con la Reina Victoria de Inglaterra.

\footnotetext{
${ }^{48}$ ALBA, JACOBO FITZ-JAMES STUART Y FALCÓ, DUQUE DE, Discurso sobre la Emperatriz Eugenia en la Academia de Doctores del Distrito Universitario de Barcelona. Curso 1946-47, Diana Artes Gráficas, Madrid, 1947, p.2

${ }^{49}$ SENCOURT, R., Napoleon III: The modern Emperor, D. Appleton-Century, Nueva York, 1933, p. 141.

${ }^{50}$ Ibidem, p.22
} 
La mayor alegría de la vida de Eugenia fue, sin duda, el nacimiento de su hijo, un deseado Príncipe heredero. Aunque no estuvo exento de graves complicaciones para la madre, tal como expone el Duque:

"El alumbramiento del Príncipe Imperial estuvo a punto de costar la vida a la Emperatriz. Al darle a luz quedó ya incapacitada para tener más hijos; este nacimiento fue, según creo, el momento más feliz del matrimonio imperial y del régimen. ${ }^{.51}$

El nacimiento del heredero tuvo como secuela para la madre la imposibilidad de concebir más hijos, aunque su alegría, como madre y como Emperatriz, fue máxima. Aunque la felicidad de dar a luz a un heredero a Napoleón III, no evitó que Eugenia tuviera que afrontar otras dificultades en su relación matrimonial con el Emperador, tal como refiere el Duque

"Aquella felicidad intima hubiera perdurado a no ser por las constantes infidelidades de Napoleón, pues Eugenia sentía sincero afecto por su marido y admiraba sus grandes cualidades. Pero por muy tormentosas que fueran las relaciones de los cónyuges, la fidelidad de ella fue absoluta y no falló en ningún momento." ${ }^{52}$

Doña Eugenia, sin embargo, pese a las infidelidades de su marido, se atuvo siempre al compromiso sacramental contraído con él y le fue fiel, según el testimonio de su sobrino-nieto. Es otro ejemplo de cómo el sentido del deber, de su posición y de su fe cristiana imperaron por encima de otros sentimientos y sirvieron de motivación de muchas de sus actuaciones, no solo en el ámbito público, sino también en la esfera privada.

Sobre la relación de la Emperatriz con su hijo, hay una obra titulada The Empress Eugénie and her son, de Edward Legge, donde expresamente se relata cómo fue la relación entre ambos:

"You ask me to give you my sincere impression respecting the relations which existed between the Prince and the Empress, between the son and the mother. In all truth, on both sides they were characterised by the deepest affection; a deferential tenderness on the part of the Prince, a passionate tenderness on the part of his mother. I lived with them for many years, and I never saw anything but the affectionate respect, manifested with the tact of a perfect gentleman, which was the Prince's distinctive characteristic. I never saw anything but the ardent and

\footnotetext{
${ }^{51}$ Ibidem.

${ }^{52}$ Ibidem.
} 
passionate affection shown by the Empress which adorned this triple character: that affection of the mother for her son, that unique love for her son of the woman who had lost everything else, the affection of the Sovereign for the last hope of her Dynasty." 53

Ambos lados se caracterizaron por el más profundo afecto: una ternura deferente, refinada, por parte del joven Príncipe, y una ternura apasionada, por parte de su madre. Ello, según el testimonio de alguien que convivió muchos años con ambos, como es el caso de Edward Legge configura un testimonio verídico en el que cabe destacar la sinceridad entre realista y melancólica que se adivina en la afirmación de "ese amor único por su hijo de una mujer que había perdido todo lo demás." 54 Tras esa enigmática afirmación de Legge probablemente se manifiesta veladamente que el gran amor de Eugenia en algunos momentos de dificultad en su matrimonio fue el amor de su propio hijo.

Y añade el propio Legge sobre la vida del heredero del trono imperial de Francia y la relación con su madre:

"The Prince Imperial enjoyed in everything the fullest liberty; he never misused it, and nothing tarnished the admirable dignity of his life. None of the divergences or discussions which might arise between two equally ardent natures ever appeared to me to be serious: they never exceeded the limits of the disquieting and jealous tenderness of a mother who has nothing in the world but her son, and which sometimes led her involuntarily to forget that she had before her not a child, but a man - a mother who would remove from his path all dangers and all intrigues. On the other side was the impatient feeling of the young man who, conscious of his strength, regarded as useless the solicitude and the precautions accumulated by the mother's alarmed affection. ${ }^{55}$

Es muy bonita la sutileza del testimonio que refiere Legge sobre la relación entre la Emperatriz y el Príncipe: Nunca sobrepasaron los límites de la ternura inquietante y celosa de una madre que no tiene en el mundo más que su hijo, y que a veces la lleva involuntariamente a olvidarse de que no tenía ante sí a un niño, sino a un hombre, una madre que apartaría de su camino todos los peligros y todas las intrigas. $^{56}$

También es muy sustancioso el testimonio de Legge sobre el momento de la despedida entre madre e hijo, antes de la partida del Príncipe:

${ }^{53}$ LEGGE, E., The Empress Eugénie and her son, New York, Dodd, Mead and company, 1916, pp. 52-53.

${ }^{54}$ Ibidem, p. 53 (en libre traducción que hacemos de la expresión original del autor referida en la cita anterior).

${ }^{55}$ Ibidem.

${ }^{56} \mathrm{Ibidem}$. 
"A profound Catholic, a worthy godson of the immortal and saintly Pius IX, his last visit on English soil was to that little church at Chislehurst in which his father reposed, and to which I alone accompanied him when, on the $26^{\text {th }}$ of February, 1879, an hour before his departure for the Cape, he repaired thither at dawn to receive his God. His filial affection led him also, while he yet stood upon English soil, to bestow his last look and his last embrace upon his mother, whose tears and grievous swoons seemed to prophesy the coming catastrophe."57

Profundo católico, digno ahijado del inmortal y santo Pío IX, su última visita en suelo inglés fue a esa pequeña iglesia de Chislehurst en la que reposaba su padre, y a la que solo yo lo acompañé cuando, el 26 de febrero de 1879, una hora antes de partir hacia el Cabo, se dirigió allí al amanecer para recibir a su Dios ${ }^{58}$. Es el testimonio impresionante con que describe Legge la marcha del Príncipe de su tierra.

Sobre la despedida con su madre -añade Legge- en el afecto desmedido con que se despidieron madre e hijo, antes de la partida del Príncipe, se presagiaba la tragedia que estaba por venir.

Sobre el carácter y la forma de ser del joven Príncipe, refiere Legge lo siguiente:

"As to his life, it was as limpid and pure as water from the crystal rock, and it was with the fullest truth and justice that Cardinal Manning, when preaching his funeral sermon at Chislehurst on the day following the obsequies, was able to hold him up as an example to all Christians, as a model of virtue to all young people, and of heroism to all soldiers. In his last prayer he offered himself as a sacrifice to God for the welfare of all. He concluded one of the few political addresses which he made with the words: «May God watch over France and restore her prosperity and her greatness!»»"${ }^{\circ 9}$

El cardenal Manning, al predicar su sermón fúnebre en Chislehurst al día siguiente de las exequias, supo ponerlo como ejemplo de virtud a todos los jóvenes. En su última oración -destacó- se ofreció a sí mismo como sacrificio a Dios por el bienestar de todos. Y concluyó su vida gritando «¡Dios vele por Francia y restaure su prosperidad y su grandeza!»

Sabido es, que el Emperador tuvo varias amantes y diversas relaciones. No todas las mujeres que se acercaban al Emperador eran por meras razones de atracción personal o seducción, sino, como suele suceder en estos casos, por otros velados intereses. Como verídicamente expone el Duque:

\footnotetext{
${ }^{57}$ Ibidem, p. 54

${ }^{58}$ Ibidem.

${ }^{59}$ Ibidem.
} 
"Entre las numerosas aventuras eróticas de Napoleón la vida no le resultaba fácil. Una de las más famosas tuvo como protagonista a madame de Castiglione, belleza italiana que dicen haber sido subvencionada por Cavour quizá con fines políticos. (...) Los ideales de la «Italia Una» perturbaban la política europea. En 1858 cierto conspirador italiano, Orsini, atentó contra la vida de Napoleón III lanzando una bomba, ante la Opera, destinada a matarle." ${ }^{` 00}$

Algunas de tales aventuras fueron con amantes no ajenas a otros intereses al servicio de causas políticas, en particular relacionadas con la causa italiana que se estaba dirimiendo en esos momentos y en la que Francia jugaba un papel decisivo.

\subsection{De las regencias de Francia al apoyo a Austria.}

Precisamente, en aquel tiempo se produjo el movimiento de liberación italiano que conduciría a la guerra por la unidad italiana y que supuso ocasión para que Doña Eugenia tuviera que asumir la regencia de Francia:

"En 1859 sobrevino la guerra de la liberación de Italia. Durante la ausencia de Napoleón actuó la Emperatriz como Regente y supo mantenerse a la altura de sus deberes. Aquella guerra fue tal vez un error por contribuir a la unidad italiana y a la abolición de los Estados Pontificios. La Soberana, que era profundamente religiosa, defendió continuamente al Papa. Y Roma no pudo ser la capital de la Italia Unida mientras una guarnición francesa defendió la ciudad pa pal contra los ataques de Víctor Manuel y de Garibaldi. Hasta 1870, en que fueron retiradas las tropas francesas, no pudo Víctor Manuel atravesar la Porta Pía, comenzando entonces el largo cautiverio de los Papas, que no ha terminado sino muy recientemente, merced al Convenio a que llegaron $\mathrm{Su}$ Santidad y Mussolini." ${ }^{\prime 61}$

En congruencia con su fe cristiana, Doña Eugenia apoyó y defendió al Santo Padre en Roma, donde una guarnición francesa le protegía. En esas actuaciones, que le otorgaron a Francia nuevas posesiones, se consolidó la fase de máximo esplendor del II Imperio francés, que supuso una etapa de enorme prestigio para Doña Eugenia:

"Aunque aquella campaña tuvo el doble efecto de hacer surgir un estado rival en el Sur de Europa y reducir y debilitar a Austria, fue un gran éxito militar que valió a Francia parte de Saboya, incluida Niza. El prestigio del segundo Imperio

${ }^{60}$ ALBA, JACOBO FITZ-JAMES STUART Y FALCÓ, DUQUE DE, Discurso sobre la Emperatriz Eugenia en la Academia de Doctores del Distrito Universitario de Barcelona. Curso 1946-47, Diana Artes Gráficas, Madrid, 1947, p.2

${ }^{61}$ Ibidem, pp.23-24. 
alcanzó su mayor altura. París llegó a ser el centro de la vida europea y más que nunca el de la elegancia, sobre la cual ejercía la Emperatriz influjo soberano, lo que no la impedía compartir los deberes del gobierno, porque, desde su Regencia, ya siempre asistió a los Consejos de Ministros." ${ }^{\prime 62}$

En el momento de máximo prestigio del II Imperio francés, París era el centro de la vida y de la diplomacia europea. Tras sus etapas como regente, Doña Eugenia se incorporó a los Consejos de Ministros. En ese contexto, la Emperatriz Eugenia proyectaba sus formas de hacer y de llevar los asuntos, pero también su imagen, su estilo y su estética a toda Europa.

En aquella etapa feliz de su vida, durante una visita a Argel, acontece un acontecimiento fatal para Doña Eugenia:

"En 1860, acompañada del Emperador, hizo un viaje triunfal a Argel; pero tuvo que interrumpirle por el mal estado de salud de mi abuela, su hermana. Regresó rápidamente a París, sin tiempo ya para despedirse de ella, pues había muerto pocos días antes. Su pena fue intensísima, ya que, como he dicho, el cariño a su hermana cuenta entre los más arraigados afectos de su vida." ${ }^{\circ 3}$

Cuando volvió a París, su hermana Paca, la abuela del Duque, ya había fallecido. Fue una de las grandes pérdidas de su vida, el no poder despedirse de su hermana como hubiera deseado.

A pesar de las críticas a su nacionalidad española que siempre le reprocharon sus detractores, por su educación francesa y sus largas estancias en la nación gala, Doña Eugenia, tal como refiere el Duque

"Nunca se juzgó extranjera en Francia, donde se había educado y vivido después muchos años; pero desde su matrimonio se consagró por entero a servir los intereses de su nueva patria, aunque sin olvidar la de origen, razón por la cual, para poder contemplar, al menos de lejos, las montañas españolas, se hizo construir un palacete en Biarritz, convirtiendo esta playa de pescadores en una de las más bellas y elegantes del mundo." ${ }^{\circ 4}$

Doña Eugenia se dedicó por entero a servir a los intereses de la nación gala, aunque sus detractores siempre recordaran sus orígenes españoles, especialmente en los momentos de zozobra y dificultad. Como refiere su sobrino-nieto siempre conservó su añoranza de España por lo que decidió construirse la residencia de Biarritz.

Entre los ilustres visitantes del palacete de Biarritz figuró alguno que luego sería un enemigo declarado de la nación gala:

\footnotetext{
${ }^{62}$ Ibidem, p. 24

${ }^{63}$ Ibidem, pp. 24-25.

${ }^{64}$ Ibidem, p. 25
} 
"Entre los visitantes de Biarritz figuró el Conde de Bismark, que ya entonces se preparaba para humillar a Francia. En 1866 declaró Prusia la guerra a Austria. Fue una guerra corta, porque la batalla de Sadowa permitió aniquilar las fuerzas austríacas en muy pocas horas. La Emperatriz se declaró partidaria de que se ayudase a Austria que, como país católico, gozaba de sus simpatías, pero la salud del Emperador era cada vez más precaria, Francia se abstuvo de intervenir hasta cuatro años después, en que fué ella misma atacada, y entonces Austria permaneció también neutral. Quizá acertaba la Emperatriz en su juicio sobre la situación." ${ }^{95}$

Sencourt atribuye todo el protagonismo de la situación bélica propiciada por Prusia a las argucias de Bismark: "It was Bismark rather than Pussia which was the lion. He declared war with Austria on $19^{\text {th }}$ June." ${ }^{\text {66 }}$

También refleja Sencourt cómo Eugenia trató de contrarrestar el drama que se adivinaba, no ya solo para Austria, sino para los destinos de la nación gala, tanto en Europa como en América:

"We have seen why there had not long been an Alliance between Paris and Vienna. It was because the gullible Rechberg, with his blind trust in Bismark, had turned with scorn from the shrewd proposal of Napoleon and Eugénie. In those fateful days of this short war, the Empress fought desperately to carry her project through. ( $\mathrm{Y}$ añade en nota: The fearful drama of the scenes in the councils and Eugénie's proposal that she should force the Emperor to abdicate and assume the regency, the author has told already in the Empress Eugénie.) But it was now too late. Behind her was a failure in Mexico, and the Emperor could not rely on carrying France with him. He had gone wrong in all his calculations. ${ }^{97}$

Prusia derrotó a Austria en siete semanas -los alemanes conocen esta batalla por ese nombre- a la que nosotros denominamos la batalla de Sadowa (1866), con la consabida neutralidad francesa, por lo que luego Francia no pudo solicitar la ayuda austriaca cuando se hubo de enfrentar, solo unos años después y en solitario, ya no solo a Prusia, sino a la confederación germano-prusiana en alianza fraguada por el Conde de Bismark al servicio del káiser Guillermo I de Prusia.

Nunca se entendió bien por qué Francia y Austria no alcanzaron un acuerdo a tiempo para enfrentarse a la Prusia de Bismark conjuntamente. Tiempo después de la derrota francesa ante la confederación germano-prusiana de 1870-71, la emperatriz Eugenia visitó al emperador de Austria, en 1906, para explicarle los motivos y que en la prensa italiana y francesa se publicaran una serie de artículos,

${ }^{65}$ Ibidem, p.25

${ }^{66}$ SENCOURT, R., Napoleon III: The modern Emperor, D. Appleton-Century, Nueva York, 1933, p. 141.

${ }^{67}$ Ibidem. 
cartas y entrevistas, que explicasen por qué Francia entró sola en la guerra con Prusia. El fracaso de la triple alianza entre Francia, Austria e Italia y la actuación de la Emperatriz es expuesta por Legge de esta forma:

"One result of the Empress Eugenie's visit to the Emperor of Austria in 1906 was to produce in the Italian and French Press a number of articles, letters, and interviews, seeking to explain why France entered single-handed into the war with Prussia. Count Constantin Nigra, better known as the Chevalier Nigra, a former Ambassador of Italy at Vienna, who died in 1907, was credited with the authorship of an article in the Tribuna narrating the history of the pourparlers between Austria, Italy, and France, prior to 1870 , having for their object a triple alliance against Prussia; and asserting that the reason of the Empress's journey to Ischl was to be found in her desire to restore to the Emperor of Austria an autograph letter sent by His Majesty to Napoleon III, making it clear to the latter that such an alliance was possible only on condition that the Emperor of the French agreed to an Italian occupation of Rome." 68

La realización de la alianza entre Francia, Austria e Italia para enfrentarse a los prusianos pasaba por la aceptación por parte de Napoleón III de la ocupación italiana de Roma. El Emperador no aceptó nunca estos términos y finalmente Francia marchó en solitario hacia una guerra hábilmente propiciada por el Conde de Bismark.

En la definitiv batalla contra la coalición germano-prusiana, que tuvo lugar en Sedán, entre el 1 y el 3 de septiembre de 1870, fue capturado el propio Napoleón III y colapsó el II Imperio francés.

Cuando Doña Eugenia, ya en Inglaterra, tuvo noticias de la captura del Emperador por parte de los prusianos, al día siguiente de la batalla de Sedán, su reacción fue en primera instancia de sorpresa e incredulidad. Según recoge Legge:

"When, the day after the battle of Sedan, the Prince de la Tour d'Auvergne officiall informed the Empress Eugenie that the Emperor was a prisoner, she exclaimed: «You lie, sir! He is dead!»"

Doña Eugenia consideró la comunicación una mentira piadosa a la esposa, que encubría la noticia del probable fallecimiento del Emperador durante la batalla. Sin embargo, posteriormente, recibió un comunicado del propio Emperador, tal como reproduce Legge:

\footnotetext{
${ }^{68}$ LEGGE, E., The Empress Eugénie, 1870-1910: Her Majesty's life since "the terrible year." Together with the statement of her case, the Emperor's own story of Sedan, an account of his exile and last days, and reminiscences of the Prince imperial, from authentic sources (With Illustrations and facsimile letters), New York, C. Scribner's sons, 1910, p. 151.

${ }^{69}$ Ibidem, p. 1.
} 
"Later, M. de Vougy handed her a telegram, and she read: «The army is defeated. I am a prisoner. - Napoleon.»»"70

No había duda de la derrota francesa y de la captura del Emperador, pero al menos tenía constancia de que su esposo estaba vivo. A pesar de la adversidad en el discurrir bélico y de la captura del Emperador, Francia no capitulaba y la guerra continuaba. Tal como expone Legge:

"The war was raging, the siege of Paris had begun, Napoleon III. was still the King of Prussia's prisoner at Wilhelmshohe, when, in the autumn of 1870, the Empress Eugenie and the Prince Imperial took up their abode at Camden Place, Chislehurst." 71

La Emperatriz y su hijo se instalaron en Camden Place, en Chislehurst, en las cercanías de Londres, al sudeste de la capital británica, a la espera de más noticias sobre el paradero del Emperador. Finalmente, días después, Napoleón III sería liberado por los prusianos.

Aunque Francia continuó luchando durante un tiempo ante la coalición germano-prusiana, bajo la dirección coyuntural de un Gobierno de Defensa Nacional de corte republicano, la inevitable derrota final sobrevino a inicios del año 1871. Para Francia supuso el fin del II Imperio, un cambio de régimen político y la reinstauración de la República, con la marcha al exilio definitivo para la familia imperial francesa.

La victoria germana sobre Francia supuso, además, para Prusia, la consolidación de su hegemonía centro-europea y la extensión de su influjo sobre los Estados y Reinos alemanes, que habían participado en la coalición triunfadora liderada por Prusia sobre el II Imperio francés, y que determinaría la unificación de Alemania bajo la iniciativa prusiana. Sedán se convirtió en todo un símbolo del orgullo patrio germano, referente triunfal de la adscripción y confluencia de los diversos estados y reinos germanos en la Alemania unificada.

\subsection{Del declive personal a su presencia en grandes eventos históricos.}

Mientras se deterioraba la posición francesa y mermaba su influjo en Europa frente a nuevas potencias emergentes en Centroeuropa como Prusia, en América los intereses franceses también se encontraban en una situación cada vez más comprometida. Así lo refiere el Duque

\footnotetext{
${ }^{70}$ Ibidem.

${ }^{71}$ Ibidem.
} 
"Mientras se desenvolvían los asuntos de Europa en contra de Francia, la aventura mejicana ocasionó al segundo Imperio gran pérdida de prestigio, que alcanzó a la Emperatriz Eugenia, patrocinadora de esta empresa. Todavía acrecentó la dureza de tales golpes la suerte fatal de la Emperatriz Carlota, conocida ya por el nombre de la «Emperatriz loca», a causa del fusilamiento del Emperador Maximiliano." 72

Eugenia había apoyado a Austria, tanto en Europa, como en América, donde se había intentado la implantación de la dinastía austriaca en Méjico, con la final dad de consolidar una monarquía católica europea en América Central, que ejerciera de contrapeso al influjo creciente de los Estados Unidos de América, de religión protestante. Con Maximiliano I de Méjico, segundo de los tres hermanos del emperador Francisco José de Austria y Emperador de la nación americana entre 10 de abril de 1864-15 de mayo de 1867, se hizo realidad este proyecto de injerto de una monarquía europea en América en pleno siglo XIX. Tanto se implicó la Emperatriz Eugenia en el apoyo a Austria y en la consolidación de la de la monarquía austriaca en Méjico, que el fracaso final de esta empresa también repercutiría sobre su persona y su prestigio.

A final s del siglo XIX se produjeron, no obstante, otros dos importantes eventos -liderados por Europa y con amplia repercusión mundial- en los que Doña Eugenia estuvo presente como mandataria europea. Tal como refiere el Duque en su discurso de Barcelona:

"Dos acontecimientos de gran esplendor se celebraron por entonces: la Exposición de París de 1867 y la apertura del Canal de Suez, por la Emperatriz, en 1869, después de una visita al Sultán de Turquía en Constantinopla, que pueden señalarse como la meta de aquel reinado. Sobre todo, la ceremonia de la apertura del Canal, fue algo fantástico, que afectaría grandemente a la viva e impresionable imaginación de Eugenia de Guzmán, al verse en aquel momento solemne representando a la gran nación que abrió a los navegantes y al comercio una vía marítima tan indispensable. Por cierto, que no faltó en la inauguración la nota pintoresca y andalucista que confirma el genio abierto de la Emperatriz. Concurría a la fiest oficial, en representación de España, la fragata «Berenguela» y sus oficiales jóvenes acordaron obsequiar una noche a su compatriota granadina con una rondalla al estilo de su tierra. Recorrieron, en un bote, el fondeadero del «Aigle», donde se alojaba la Emperatriz, cantando coplas andaluzas acompañados de guitarras y, para corresponder al obsequio, ella se asomó a la borda y cantó la copla:

«La pena y la que no es pena,

no son penas para mí.»

${ }^{72}$ ALBA, JACOBO FITZ-JAMES STUART Y FALCÓ, DUQUE DE, Discurso sobre la Emperatriz Eugenia en la Academia de Doctores del Distrito Universitario de Barcelona. Curso 1946-47, Diana Artes Gráficas, Madrid, 1947, p.2 
Puede suponerse el efecto que en los estirados marinos franceses causaría tal rasgo de popularidad y casticismo de su soberana." 73

El Canal de Suez era una arteria de comunicación del Mediterráneo con el Océano Índico por vía marítima, que aún hoy es el medio por donde transita todo el tráfico euro-asiático de mercancías, por lo que este canal permitía una cación del tráfico comercial con Oriente y un acortamiento muy importante de la distancia que separaba a Europa de Asia Oriental.

Sobre la importancia decisiva para Europa de la realización de la infraestructura del Canal de Suez exponía Julián Marías, en un curso titulado Génesis y realidad de Europa, lo siguiente:

"Hubo un momento de plenitud, el 17 de noviembre de 1869, fecha de la inauguración del Canal de Suez. Triunfo de la técnica física, de las técnicas económicas y sociales. Es la época de la Inglaterra victoriana. Asistió a la ceremonia de inauguración el emperador Francisco José de Austria. Así como la esposa de Napoleón III: Eugenia de Montijo. Con las escuadras de los principales países presentes en el acto. Es un momento de plenitud. Los pueblos de Europa se reúnen en una fiesta. ${ }^{74}$

Julián Marías refiere la relevancia de este evento histórico, que para Europa significó la confluencia de las diversas naciones en la realización de esta decisiva infraestructura, y subraya expresamente la presencia de Eugenia de Montijo, como mandataria europea, junto al Emperador de Austria, en la inauguración de la importante infraestructura de interconexión marítima con Asia.

En su vida personal y familiar, su hijo, el Príncipe heredero era un joven encantador y profundamente religioso. Sobre esta religiosidad del Príncipe, el Duque refiere lo siguiente

"El Príncipe iba creciendo y mostraba poseer una personalidad encantadora. Era, en cierto modo, un místico, y escribió una muy bella oración que se ha conservado." 75

El joven Príncipe unía su profundo sentimiento religioso con la sensibilidad literaria para expresarla por escrito, lo cual subraya la importancia que él mismo confería a su fe religiosa.

\footnotetext{
${ }^{73}$ Ibidem, p. 27

${ }^{74}$ MARÍAS AGUILERA J., Génesis y realidad de Europa, Curso en el Colegio Libre de Eméritos, Madrid, 1991. Disponible en

https://arealidadensuconexion.blogspot.com/2017/06/genesis-y-realidad-de-europa.html

${ }^{75}$ ALBA, JACOBO FITZ-JAMES STUART Y FALCO, DUQUE DE, Discurso sobre la Emperatriz Eugenia en la Academia de Doctores del Distrito Universitario de Barcelona. Curso 1946-47, Diana Artes Gráficas, Madrid, 1947, p.34
} 
Sobre su formación militar, propia de su condición, y las desventuras que ella le traería, añade el Duque algunos datos biográficos relevantes

“Siguiendo la tradición napoleónica, entró de artillero en Woolwich. Viajó mucho con su madre y pasó temporadas en Suiza, pero su residencia permanente siguió siendo Inglaterra. Sobrevino después la expedición a Zululandia. El Príncipe resolvió ir. La Emperatriz le negó el permiso, pero después de largos forcejeos consiguió alcanzarle. Desde el principio le persiguió la mala suerte. Tuvo que marchar precipitadamente sin tiempo para reunir un equipo adecuado, y hubo de comprar lo que encontró hecho, entre otras cosas, una silla de montar sin tiempo para encargarla a propósito. Una vez en Zululandia, le contrariaron las preferencias de que se le hacía objeto; por ejemplo, la de formar una guardia de swazis para su personal protección, lo cual le molestaba mucho si bien no podía impedirlo." 76

En su formación entraba su adiestramiento en el arte militar, que realizó en Suiza, aunque siguió conservando su residencia en Inglaterra. En servicio a esta nación marchó como expedicionario a África, a la región de los zulúes. Como personalidad destacada en la expedición, el Príncipe iba acompañado de una pequeña escolta como medida de protección ante posibles incidentes, compañía que el joven consideraba inapropiada e innecesaria, como bien refiere el Duque en su discurso.

\section{Tras la muer te del Emperador.}

El declinar de la influencia de Doña Eugenia, ya en su exilio en Inglaterra, aún conocería nuevas desgracias que estaban por venir. Serían episodios más tristes, si cabe, porque le afectarían en el ámbito familiar más próximo. El primero de esos eventos fue la muerte de su esposo, el Emperador.

\subsection{De la muerte del Emperador a la del Príncipe.}

Napoleón III falleció el 9 de enero de 1873, en Londres, en el exilio, justo dos años después de la derrota frente a la confederación germano-prusiana que puso fin al II Imperio francés. Fue el último monarca que tuvo Francia, porque, como hemos expuesto, a su fallecimiento siguió la creación de un Gobierno de Defensa Nacional para terminar la guerra contra los germanos y luego sobrevino la reinstauración de la República.

Sobre las circunstancias que rodearon y causaron el fallecimiento del Emperador, ya en el exilio, hubo cierta especulación porque en fechas previas había

\footnotetext{
${ }^{76}$ Ibidem, p.34.
} 
sido sometido a una operación quirúrgica, que hoy se considera que no fue determinante de su muerte a la edad de 64 años, que podemos juzgar temprana desde parámetros actuales, y que no lo es tanto si consideramos las verdaderas razones de su fallecimiento y los antecedentes familiares que le precedían, tal como han puesto de relieve algunos estudiosos extranjeros sobre las circunstancias que rodearon y desencadenaron su fallecimiento.

Edward Legge, en un capítulo titulado «sobre las verdaderas causas del fallecimiento del Emperador», refiere así la muerte de Napoleón III

"On January, 9, 1873, Napoleon III died at Chislehurst, to the dismay and bewilderment of the little Court at Camden Place and of his numerous friends in France and England. It was shortly before Christmas that the imperial household had begun to vaguely realize that the Emperor was seriously ill. He himself had no idea of his approaching end." $" 77$

Legge, que ha estudiado a fondo el fallecimiento y dedica todo un capítulo entero a esta cuestión, refiere que Napoleón falleció tempranamente y que no fue debido a la operación a la que había sido sometido en fechas previas a su fallecimiento. Así refiere Legge, las verdaderas causas del fallecimiento del Emperador

"Had Napoleon III, who died on January 9, survived until April 20, he would have entered upon his sixty - fifth year. Napoleon I died at the early age of fifty two, his father at thirty-nine, and his grandfather at the same age; and, according to M. Frederic Masson, of the Académie Française, all three died of a cancerous affection of the stomach. ${ }^{78}$

El emperador Napoleón III falleció por un cáncer estomacal de una forma prematura análoga a otros miembros de su misma familia: Napoleón I -expone Legge- falleció a la temprana edad de 52 años. Su padre a los 39 años y su abuelo a la misma edad. Luego había antecedentes familiares muy claros y contrastados, según apunta Legge en su estudio. Hoy, más de cien años después de la obra en que esta circunstancia queda referida, sabemos que la predisposición genética y los antecedentes familiares constituyen dos de los factores de riesgo preponderantes para el diagnóstico de la enfermedad.

Tan solo seis años después del fallecimiento del Emperador, la tragedia se cerniría de nuevo sobre la familia con la muerte del Príncipe en acto de servicio

${ }^{77}$ LEGGE, E., The Empress Eugénie, 1870-1910: Her Majesty's life since "the terrible year." Together with the statement of her case, the Emperor's own story of Sedan, an account of his exile and last days, and reminiscences of the Prince imperial, from authentic sources (With Illustrations and facsimile letters), New York, C. Scribner's sons, 1910, p. 74.

${ }^{78}$ Ibidem, p. 89. 
durante una expedición en África, en una emboscada zulú. Así refiere el Duque las circunstancias que rodearon la muerte del Príncipe:

"El día fatal I I de junio de 1879, esta guardia no estaba con él a causa de un error en la transmisión de las órdenes, y tuvo que salir, con muy reducida tropa, bajo el mando del Capitán Carey, a explorar sitio adecuado para el próximo campamento. A su llegada al África del Sur había comprado el Príncipe un caballo de tan buena estampa como mala boca. Gracias a ser consumado jinete logró dominar al animal. En la tarde de aquel día, después de haber tomado algunos croquis topográficos, se sentaron todos a descansar. De pronto les sorprendieron, en gran número, los zulús, que se habían acercado ocultos por las altas hierbas, acometiéndoles con gritos salvajes entre los disparos de u nos cuantos viejos fusiles. Murieron dos soldados. Carey se lanzó sobre su caballo y salió al galope. El Príncipe, siguiendo su costumbre, se agarró a las pistoleras de la montura para saltar sobre el animal, pero éste se encabritó y trató de seguir al galope al del Capitán Carey y a los demás. Las pistoleras se rompieron y se quedaron en las manos del Príncipe, que se vió solo frente al enemigo. Le hizo cara con valor sacando su espada y muriendo como un héroe. He examinado varias veces su uniforme: tiene en el pecho dieciséis cuchilladas de azagaya; ni una sola en la espalda. Su cuerpo quedó allí hasta que poco después fué entregado por el Rey de los Zulús, Cetiwayo." 79

El joven Príncipe, ávido de aventuras en tierras exóticas, encontró la muerte en una de sus primeras peripecias al servicio de la Corona inglesa en tierras africanas, aunque afrontó la muerte con valentía y coraje, como bien atestiguaron las secuelas del enfrentamiento en que encontró la muerte, según el testimonio del Duque.

El drama personal y el dolor que supuso para Doña Eugenia, que tan solo seis años de fallecer su esposo, tuvo que afrontar la muerte de su único hijo, durante su exilio en Inglaterra, solo es comparable al drama que vivirían muchas familias europeas poco tiempo después en un conflicto armado de proporciones inimaginables.

\subsection{Del Exilio en Inglaterra a la I Guerra Mundial.}

Sobre los primeros meses de su exilio en Inglaterra, escribe Legge en su obra sobre Doña Eugenia, titulada The Empress Eugénie, 1870-1910: Her Majesty's life since "the terrible year", lo siguiente:

${ }^{79}$ ALBA, JACOBO FITZ-JAMES STUART Y FALCÓ, DUQUE DE, Discurso sobre la Emperatriz Eugenia en la Academia de Doctores del Distrito Universitario de Barcelona. Curso 1946-47, Diana Artes Gráficas, Madrid, 1947, p. 34 -35 
"From the earliest days of her arrival in England, the Empress devoted herself to the greatest task of her life - the effort to arrange terms of peace. It was still September, the month of Sedan. The Germans were marching on Paris, which they girdled on the $19^{\text {th }}$, eleven days after the Empress had found a refuge at Hastings; Metz and Strasburg were besieged; Gambetta was organizing the army of national defence; many months of warfare were before the combatants." $\$$

Mientras los alemanes marchaban hacia París, la Emperatriz trataba de entablar negociaciones de paz al tiempo que buscaba refugio, lo cual hizo en Hastings, Metz y Estrasburgo.

En la localidad de Farnborough, en el condado de Hampshire, al Sur de Inglaterra, Doña Eugenia adquirió una propiedad donde construiría una cripta funeraria - para su marido y su hijo-, como bien refiere su sobrino-nieto

"Compró en Inglaterra la finca de Farnborough donde construyó la cripta en que yacen el Emperador y el Príncipe y donde la enterramos a ella en 1920, depositándola en el muro para cumplir sus deseos de no ser puesta en la tierra, y con la sencilla inscripción «Eugenie» en la lápida. Junto a la nca edi có también un Monasterio de monjes franceses, en un principio de la Orden Premostratense, y hoy de Benedictinos, que todavía siguen allí." ${ }^{81}$

Finalmente, en su residencia de Farnborough, en la misma cripta que Doña Eugenia levantó para acoger los restos del Emperador y del Príncipe, descansan también sus propios restos, como refiere su sobrino-nieto, quien la visitó allí en varias ocasiones, puesto que el Duque estudió cerca de allí, como ya se ha expuesto anteriormente.

Poco tiempo después el dolor de Doña Eugenia por su marido y su hijo se harían extensivas a otras muchas familias europeas que se vieron inmersas en un enfrentamiento internacional, en un nuevo tipo de conflict masivo y mecanizado que costó la vida a millones de jóvenes, hijos y esposos de muchas mujeres de casi todas las naciones europeas.

El Duque refiere las impresiones y actuaciones de Doña Eugenia durante la I Guerra Mundial, la cual vivió y siguió con gran preocupación e interés desde Inglaterra:

${ }^{80}$ LEGGE, E., The Empress Eugénie, 1870-1910: Her Majesty's life since "the terrible year." Together with the statement of her case, the Emperor's own story of Sedan, an account of his exile and last days, and reminiscences of the Prince imperial, from authentic sources (With Illustrations and facsimile letters), New York, C. Scribner's sons, 1910, p. 21.

${ }^{81}$ ALBA, JACOBO FITZ-JAMES STUART Y FALCÓ, DUQUE DE, Discurso sobre la Emperatriz Eugenia en la Academia de Doctores del Distrito Universitario de Barcelona. Curso 1946-47, Diana Artes Gráficas, Madrid, 1947, p. 38 
"En 1914 la gran guerra causó a la Emperatriz terrible ansiedad. Tenía que permanecer en Inglaterra y no podía pasar el invierno, como de costumbre, en el Mediodía de Francia: pero su maravillosa constitución la permitió resistir la humedad y sus frecuentes constipados. Durante las primeras semanas de la guerra, que la causaron gran impresión, exclamaba, presa de gran inquietud: «C'est la meme chose qu'en 1870»" Después sobrevino el milagro del Marne. Seguía con atención la guerra día por día. Visité yo el frente francés e inglés varias veces, y a mi regreso, en Inglaterra, tuve que darla cuenta detallada de cuanto había visto. Organizó en Farnborough un hospital para oficiale heridos y se consagró ella a cuidarlos." 83

Aunque la Emperatriz llegó a pensar que se repetiría la victoria de los alemanes en la Guerra franco-prusiana de 1970, el milagro del Marne le hizo revivir la esperanza en una resolución favorable del conflicto en favor de Francia e Inglaterra. Cabe recordar que en la Gran Guerra europea se emplearon muchas novedosas armas: químicas, en forma de gases, explosivas, mecanizadas, etc. en un nuevo tipo de conflicto industrializado y a gran escala, donde los soldados fallecieron de una forma masiva y estuvieron sometidos a situaciones de estrés bélico en frentes estáticos durante meses en la denominada guerra de trincheras, causando un estrés psicológico ininterrumpido que dejaba profundas secuelas mentales. Desde su residencia en Farnborough, Doña Eugenia organizó un hospital e hizo todo lo posible por paliar las secuelas tan tremendas que este nuevo tipo de conflicto armado ocasionaba.

\subsection{Del sentido de su vida, desde la fe católica, al código de honor de la Emperatriz.}

Doña Eugenia fue una mujer católica cuya religiosidad estuvo presente en muchos de los rasgos de su personalidad y de sus actuaciones, tanto de las exitosas como de otras que no salieron como ella deseaba.

Sobre la fe religiosa de la Emperatriz, Sencourt expone lo siguiente:

${ }^{82}$ «C'est la meme chose qu'en 1870» («Es lo mismo que en 1870»): alude a la derrota sufrida por Francia ante la confederación de Prusia y los Estados Alemanes del Norte en la Guerra Franco-Prusiana de 1870-71. Tras la marcha de Napoleón III para liderar al ejército francés y enfrentarse a los alemanes, la Emperatriz Eugenia de Montijo quedó, de nuevo, como regente de Francia. No obstante, en la batalla de Sedán (1 y 2 de septiembre de 1870) Napoleón III fue capturado, aunque Francia no capituló y la guerra continuó bajo un gobierno republicano. La derrota final francesa, lograda tras el asedio alemán de París, trajo como consecuencia la caída definitiva del II Imperio francés, el advenimiento de la III República y el surgimiento del Imperio Alemán bajo la influencia prusiana. El monarca Guillermo I de Prusia fue entronizado como Emperador de la Alemania unificada en el Palacio de Versalles en París el 28 de enero de 1871.

${ }^{83}$ Ibidem, p.43 
"Yet, firm as her religion was, she was neither a mystic, a devotee, nor a theologian. Her faith was that of an intellectual. She had been educated not only by free-thinkers in France: even in Spain, her family traditions had been those of the most liberal Catholics in the country. Her feeling for her Church and its head was a reasoned allegiance; loyalty, with honour, was root of all her chivalrous virtues." ${ }^{\text {"84 }}$

Eugenia no fue una mística, una devota o una teóloga ${ }^{85}$, según refiere Sencourt. $\mathrm{Su}$ fe religiosa fue más bien la de una intelectual debido a la educación liberal europea que había recibido en Francia, que también estaba presente en su propia tradición familiar ya en España. Eugenia tenía una creencia religiosa razonada, con un sentido de la lealtad y el honor que estaban en la base de su caballeresco sentido de la virtud.

Sencourt añade algunas claves sobre la forma en que influyó el catolicismo tanto en la forma de relacionarse con el pueblo como en su acción de estado y su proyección en la diplomacia y las relaciones exteriores. Afirma Sencourt

"Her Catholicism taught her charity: and her heart was full of sympathy for those in need. But she preferred the traditions, and therefore the power, of Catholic countries to the dominance of Protestant or material civilization; her sympathy was always with Catholic influences and consecrated monarchies. Loyalty to Spain, and keenness on reform found in her broad life ample room for each other." ${ }^{96}$

Su catolicismo en relación con el pueblo lo entendió básicamente como caridad y proximidad hacia los más pobres y desfavorecidos de la sociedad; mientras que, en su acción de gobierno, su catolicismo se tradujo en tratar de apoyar, favorecer y coaligarse con las naciones católicas y las monarquías consagradas.

Siempre al servicio de su país, con gran añoranza de España y con un afán reformista de la sociedad, que no eran incompatibles en su personalidad, puesto que estuvo muy influenciada por el propio reformismo ilustrado de su familia, especialmente de su padre, y por la propia educación liberal francesa e inglesa en que se había formado.

Sobre su sentido de la caridad, Legge refiere lo siguiente

"She has always the same compassion for the unfortunate and grief-stricken. She who when on the throne was the personification of charity, the good angel of the humble, shows in exile that her benevolence was not a service practised for

\footnotetext{
${ }^{84}$ SENCOURT, R., Napoleon III: The modern Emperor, D. Appleton-Century, Nueva York, 1933, p. 141.

${ }^{85}$ Ibidem.

${ }^{86}$ SENCOURT, R., Napoleon III: The modern Emperor, D. Appleton-Century, Nueva York, 1933, p. 141.
} 
reasons of policy, but very real and abiding. Ever since, forty-five years ago, she found an asylum in England, all who have knocked at her door and appealed for help have been succoured." $" 87$

Doña Eugenia siempre sintió la misma compasión por los desafortunados y los afligidos. Cuando estaba en el trono era la personificación de la caridad, «el ángel bueno de los humildes» en expresión de Legge. Cuando se exilió en Inglaterra mostró que su benevolencia no era un servicio practicado por razones de coyuntura política o de imagen pública, sino la expresión de un principio de actuación más sólido y congruente. Desde que encontró asilo en Inglaterra, todos los que llamaron a su puerta y solicitaron su ayuda, fueron socorridos.

Sobre esta forma de entender el sentido de su vida y su responsabilidad, su sobrino-nieto el Duque de Alba y Director de la Academia de la Historia concluye afirmando

"Como epílogo quiero recordaros los conocidos versos:

«Al Rey la hacienda y la vida

se ha de dar; pero el honor

es patrimonio del alma,

y el alma sólo es de Dios.»

Durante toda su vida se mantuvo la Emperatriz rig urosamente fiel a este código del honor. No encontraría yo modo más feliz de terminar esta conferencia, ni frase capaz de superar a estas palabras a ella referentes, y pronunciadas, no por uno de sus admiradores, sino por aquel que la traicionó. Aludiendo al Consejo de Ministros celebrado durante los días críticos de 1870, bajo la presidencia de la Emperatriz, confesó Trochu, años después: «Elle nous dominait tous par sa beauté et par sa vertu»." 88

Tras su caída fueron muchos los que la envidiaban y quisieron hacer leña del árbol caído, por lo que no dudaron en difamarla y calumniarla, muchos de ellos aludiendo despectivamente a sus orígenes españoles a los que nunca renunció.

Años después de su caída, no solo sus detractores, los que no eran afines a su figura, sino declarados opositores a ella, como el ex-primer ministro Trochu,

${ }^{87}$ LEGGE, E., The Empress Eugénie and her son, New York, Dodd, Mead and company, 1916, p. 55 .

${ }^{88}$ ALBA, JACOBO FITZ-JAMES STUART Y FALCÓ, DUQUE DE, Discurso sobre la Emperatriz Eugenia en la Academia de Doctores del Distrito Universitario de Barcelona. Curso 1946-47, Diana Artes Gráficas, Madrid, 1947, p. 51. «Elle nous dominait tous par sa beauté et par sa vertu» («Ella nos dominó a todos por su belleza y su virtud») palabras pronunciadas por el ex-primer ministro francés Louis Jules Trochu, Jefe del Gobierno de Defensa Nacional durante la Guerra Franco-Prusiana (1970-71) tras el apresamiento de Napoleón III. 
reconocían la categoría personal y la virtud que acompañó la actuación de la Emperatriz española que rigió los destinos de Francia.

Cabe recordar que, en todo caso, todas las posiciones y comentarios respecto a su figura siempre fueron contempladas con serena aceptación por su protagonista, quien se negó a tratar de justificarse ante su pueblo y ante los ojos del mundo, no por soberbia, sino por haber actuado conforme a razones y criterios que en su momento consideró apropiados, condujeran luego al éxito o no.

La renuncia a publicar sus memorias todavía hizo correr más ríos de tinta sobre su persona, con intereses e intenciones no solo diversos, sino abiertamente contrapuestos. El interés por su figura se trasladó incluso al imaginario colectivo dando lugar a canciones, relatos y poemas que la inmortalizaron en la memoria popular, seguramente las contempla con gusto y sentido del humor allá donde se encuentre.

\section{Conclusiones.}

María Eugenia Ignacia Agustina de Palafox Portocarrero y Kirkpatrick (18261920), Condesa de Teba, fue una eminente mujer española, andaluza, nacida en Granada y de origen aristocrático, que alcanzó una preeminente posición como Emperatriz consorte de Francia tras su matrimonio con Napoleón III de Francia (1808 - 1873).

Hemos tratado en esta investigación de realizar una semblanza de Doña Eugenia a partir de una aproximación hermenéutica a los discursos de su sobrino-nieto, D. Jacobo Fitz-James Stuart y Falcó, Duque de Alba y Director de la Real Academia de la Historia, y hemos buscado en la extensa bibliografía extranjera el complemento más selecto y riguroso para la constatación de los hechos y de las circunstancias que el Duque refiere en sus discursos de los años 40 sobre su tía-abuela.

Nos hemos centrado en el Discurso en la Universidad de Barcelona del curso 1946-47, que hemos empleado como hilo conductor de nuestra exposición por ser cronológicamente posterior y, en cierto modo, una actualización del precedente de Oxford. Hemos considerado conjuntamente ambos documentos en nuestra consideración, aunque con una menor incidencia del de Oxford, por la abundancia de referencias en éste al contexto de postguerra en España y a la Guerra Civil Española, que poco o nada aportan a la finalidad de nuestra investigación, que es el conocimiento sosegado, científico y riguroso de la persona de Doña Eugenia de Montijo en las múltiples facetas y dimensiones de su persona.

Somos conscientes de que la presente investigación es una aproximación limitada y circunscrita a una hermenéutica de los discursos del D. Jacobo Fitz-James 
Stuart y Falcó, que necesita de ulteriores trabajos que vengan a completar el perfil de la figura de la Emperatriz, pero nos parece que la relevancia del personaje lo merece y se descubre en toda su dimensión cuando se aborda rigurosamente desde distintas obras que deben tener siempre como referente necesario los discursos y aportaciones del Duque de Alba.

Como Emperatriz de Francia, Doña Eugenia detentó la regencia directa de los destinos la nación gala y de todas sus posesiones de ultramar durante tres periodos en la época del II Imperio Francés (1852 - 1870). Cabe reseñar que tal responsabilidad la ejerció en momentos críticos para la nación gala, en ausencia del Emperador, pero adoptando decisiones exitosas que le reportaron gran prestigio. En virtud de tales aciertos en su acción de gobierno, fue incorporada a las reuniones de los Consejos de Ministros de Francia siendo promotora de diversas iniciativas relevantes, algunas acertadas y otras no tanto, pero de las que siempre asumió la responsabilidad y dio cuenta pública de las razones que las motivaron.

En su acción de gobierno y su iniciativa legislativa, Doña Eugenia se distinguió por un notable sentido de estado imbuido por su adscripción cristiana que entendió como servicio leal a los destinos de Francia y la promoción de acciones sociales caritativas, orientadas hacia los más pobres y desfavorecidos de la sociedad de su tiempo, acciones que le reportaron una gran notoriedad popular y un gran prestigio personal desde el mismo momento de su matrimonio cuando decidió donar el obsequio de la ciudadanía de París, por cuestación popular, a obras benéficas en favor del pueblo

En política exterior, mostró un apoyo decidido a las monarquías católicas, hasta donde fuera aconsejable en cada momento, teniendo siempre presente los intereses de Francia y la conveniencia y la oportunidad del momento. Sus fracasos en algunas decisiones, como el apoyo a Austria en su tentativa de implantación de la casa de Habsburgo en Méjico, le supusieron también un desprestigio y algunos cuestionamientos hacia su persona.

Como es sabido, Francia siempre ha ocupado una posición destacada en la historia de la diplomacia europea. En el complejo escenario del siglo XIX, en que se estaban configurando varias naciones de Europa, Doña Eugenia, desde París, en el epicentro de la diplomacia europea, jugó un papel notable como creadora de puentes entre las distintas naciones, prestando un valioso servicio que considera siempre los intereses franceses, pero que buscó, por encima de todo, la concordia de los pueblos y naciones de Europa. Su formación transnacional en España, Francia e Inglaterra, sin duda, posibilitó esa labor, no menos que su amplio y selecto círculo de amistades y su red de relaciones personales, que incluyeron a la Reina de Inglaterra, pero también a otras relevantes personalidades de su tiempo y cancilleres de naciones como Austria o Prusia. Su interés en los asuntos de esta- 
do, tanto a escala nacional como internacional, y su capacidad para las relaciones personales la confirieron un papel más relevante de lo que se suele considerar para una mujer que no fue solo Emperatriz consorte de Francia, sino tres veces regente de los destinos del II Imperio francés.

No menos relevante fue la labor cultural de Doña Eugenia, quien, desde una notable educación liberal europea, mantuvo una relación personal y epistolar con muchos escritores, pintores, políticos, generales, poetas e intelectuales de la época, rodeándose de un círculo a modo de corte cultural e intelectual, que también debería ser estudiado con mayor detalle.

También participó Doña Eugenia en importantes eventos históricos con un trasfondo científico-técnico, como la Exposición Universal de París de 1867 o la Cumbre de apertura del Canal de Suez en 1969, que no fue un mero evento de inauguración de una colosal infraestructura de ingeniería técnica, sino un proyecto de confluencia de las distintas naciones europeas, que conectará a Europa con Asía y el resto del mundo por vía marítima, y en el que ella participa como mandataria europea destacada junto al Emperador de Austria.

Francia siempre ha sido una nación vanguardista en la creación de estética y referencial en la creación de nuevas tendencias de estilo. En lo estético, Doña Eugenia fue un icono cultural y estético, referencia absoluta para la Europa de su tiempo. Desde su posición, ejerció un notable influjo como creadora de un estilo novedoso en las artes decorativas de la moda y en la forma de seducir y de relacionarse con las personas, con un contenido único y original, que impactó en la sociedad de su tiempo y en las sociedades de las distintas naciones de Europa.

Su negativa a escribir sus propias memorias, que hubieran sido un gran éxito editorial y despejado muchas incógnitas en el conocimiento de su persona y las motivaciones de su actuación, dejó muchas lagunas que solo paulatinamente se podrán ir desvelando. Desde luego, esa omisión consciente y deliberada de unas memorias donde narrase su vida en primera persona no impidió la aparición de una ingente bibliografía sobre su persona que se vio reflejada además en grandes retratos y obras de arte y en el imaginario popular en forma de numerosos poemas, canciones y relatos con que se rememora su persona en la cultura popular.

Habría que estudiar más profundamente, entre otros aspectos, su configur ción cristiana, su proyecto de unidad de los pueblos y naciones de Europa, para determinar si toda esta dimensión de su persona no se ha obviado quizá por ser una católica convencida en los albores del siglo XX, cuando algunas corrientes ideológicas quisieron mostrar la cosmovisión cristiana como un signo de incultura, una rémora del pasado, sin tener presente todos los hechos que aquí se relatan y el papel que Doña Eugenia desempeñó en Francia, en Europa y en el mundo 
desde una cosmovisión fundamentada en el Dios del Logos que hace desaparecer mitos y supersticiones.

La importancia histórica de la Doña Eugenia de Montijo, una mujer española Emperatriz de Francia, en su doble faceta de consorte y de regente, a la que sus detractores reprocharon siempre su condición de extranjera y su españolidad, especialmente en los momentos críticos o en las decisiones cuestionables, debería ser objeto de mayor atención y conocimiento en su propia nación, a la que siempre tuvo como referencia de sus afectos y de sus orígenes.

Su acción política y legislativa en favor de su pueblo y de la concordia entre las naciones de su tiempo, que persiguió de forma incansable, constituye un episodio muy relevante en ese camino hacia la concordia, la solidaridad y la caridad emprendida por las naciones europeas, un hito contemporáneo relevante en la propia historia de la configuración moderna de la civilización cristiana que ha tenido siempre como referencia y fundamento una estructura intelectual, moral y social sustantiva que conforman toda una cosmovisión.

\section{Bibliografía consul tada y cit ada.}

ALBA, JACOBO FITZ-JAMES STUART Y FALCÓ, DUQUE DE, Cartas familiares de la emperatriz Eugenia. Barcelona, Iberia, 1944.

ALBA, JACOBO FITZ-JAMES STUART Y FALCÓ, DUQUE DE, Discurso sobre la Emperatriz Eugenia en la Academia de Doctores del Distrito Universitario de Barcelona. Curso 1946-47, Madrid, Diana Artes Gráficas, 1947.

ALBA, JACOBO FITZ-JAMES STUART Y FALCÓ, DUQUE DE, La Emperatriz Eugenia / el Duque de Alba: Conferencia pronunciada en «The Ark», Oxford, 15 de julio de 1941, Biblioteca Virtual Miguel de Cervantes, Alicante, 2012. Disponible en http:/www.cervantesvirtual.com/obra/la-emperatriz-eugenia/

ANCEAU, E., Ils ont fait et défait le Second Empire. París, Tallandier, 2019.

ARONSON, T., Queen Victoria and the Bonapartes. Londres, Thistle Publishing, 2015.

ARTEAGA, A., Eugenia de Montijo, Martínez Roca, Barcelona, 2000.

BARKER, N., Distaff Diplomacy. The Empress Eugénie and the Foreign Policy of the Second Empire. Austin, University of Texas Press, 1967.

CARETTE, M., Souvenirs intimes de la Cours des Tuileires. París, Éditeur Paul Ollendorff, 1889

CHAUVEL, G, Eugenia de Montijo. Emperatriz de los franceses, Planeta de Agostini, Barcelona, 2001.

DARGENT, R., L'impératrice Eugénie. L'obsession de l'honneur. París, Beli, 2017.

DESCARS, J., Eugenia de Montijo. La última emperatriz. Barcelona, Ariel, 2003.

DUFF, D., Eugenia de Montijo y Napoleón III. Rialp, Madrid, 1981. 
ÉTĖVENAUX, J., Napoléon III. Visionnaire de son temps. Divonne-les-Bains, Cabédita, 2014.

FERRER VALERO, S., "La última emperatriz francesa, Eugenia de Montijo (18261920)". Blog: Mujeres en la historia, 17 de marzo de 2011. Disponible en https:// www.mujeresenlahistoria.com/2011/03/la-ultima-emperatriz-francesa-eugenia. html

GRANGER, C., L'empereur et les arts. La liste civile de Napoléon III. París, École des Chartes, 2005.

IMPÉRATRICE EUGÉNIE (DUKE OF ALBA \& GABRIEL HANOTAUX, eds), Lettres familières de l'impératrice Eugénie, París, Plon, 1871 -1872.

ITURRIAGA DE LA FUENTE, J.N., Escritos mexicanos de Carlota de Bélgica. México, Banco de México, 1992.

KIRKPATRICK, Archivo familiar: documentación y fuentes, Madrid.

LACHNITT, J.C., Le Prince impérial, Napoléon IV. París, Perrin, 1997.

LEGGE, E., The Empress Eugénie and her son, New York, Dodd, Mead and company, 1916.

LUIS, N., "Eugenia de Montijo, cien años de la influencer española más internacional del s. XIX", Revista VOGUE, 11 de julio de 2020. Disponible en https://www.vogue.es/moda/articulos/eugenia-montijo-emperatriz-francia-legado-moda-worth-alta-costura-louis-vuitton

MANEGLIER, H., Paris Impérial. La vie quotidienne sous le Second Empire. París, Editions Armand Colin, 1990.

MARÍAS AGUILERA, J., España inteligible. Razón histórica de las Españas, Madrid, Alianza Editorial, 2014.

MARÍAS AGUILERA, J., Génesis y realidad de Europa, Curso en el Colegio Libre de Eméritos, Madrid, 1991. Disponible en

https://larealidadensuconexion.blogspot.com/2017/06/genesis-y-realidad-de-europa.html

MAUDUIT, X., Le Ministère du faste. París, Fayard, 2016.

MCQUEEN, A., Empress Eugénie and the Arts. Politics and Visual Culture in the Nineteenth Century. Burlington, Ashgate Publishing, 2011.

MÉRIMÉE, P., Lettres de Prosper Mérimée a Madame de Montijo. París, Mercure de France, 1995.

MORATÓ, C., Reinas malditas, Barcelona, Plaza \& Janés, 2014.

MONTIJO E. DE, Les fiançailles de l'Impératrice: lettres a la duchesse d'Albe (SENCOURT, ed.) Revue des Deux Mondes (1829-1971), Huitième Oériode, vol. 10, $\mathrm{n}^{\circ} .2$ (15 juillet 1932), pp. 295-301.

MUSEO DEL ROMANTICISMO, Dossier de Prensa Eugenia de Montijo. La obra invitada: Eugenia de Montijo, retrato de Franz Xaver Winterhalter. Del 25 de septiembre al 9 de diciembre. Disponible en https://www.culturaydeporte.gob.es/mromanticismo/dam/jcr:fc0af878-a25e46a2- 9443-2cf2a10cc6bd/24-09-dossier-eugenia-montijo.pdf 
PINCEMAILlE, C., L'impératrice Eugénie. De Suez À Sedan. París, Payot, 2000.

PRADELLES, E., Le Prince Imperial, Napoléon IV. Correspondance inédite, intime et politique. París, Mémoire et Documents, 2009.

RIDLEY, J.G., Napoleon III and Eugenie. Nueva York, Viking Press, 1979.

SAGRERA, A., La juventud de la emperatriz Eugenia. Madrid, Compañía literaria, 1998.

SAMPEDRO ESCOLAR, J.L., La Casa de Alba. Mil años de Historia y de leyendas. Madrid, La Esfera de los Libros, 2007.

SENCOURT, R., The life of the Empress Eugénie. (With a Foreword by His Grace The Duke of Berwick and Alba), Charles Scribner's Sons, Nueva York, 1931.

SENCOURT, R., Napoleon III: The modern Emperor, D. Appleton-Century, Nueva York, 1933.

SENCOURT, R., T. S. Eliot, A Memoir. Londres, Garnstone Limited, 1971.

VV.AA., Spectaculaire Second Empire. París, Skira, 2016.

WECKMAN, L., Carlota de Bélgica. Correspondencia y escritos sobre México en los archivos europeos (1861-1867). México, Porrúa, 1989.

WELlESLEY, V. \& SENCOURT, R., Conversations with Napoleon III (a collection of documents, mostly unpublished and almost entirely diplomatic selected and arranged with introductions by Victor Wellesley and Robert Sencourt), Londres, E. Benn,1934. 